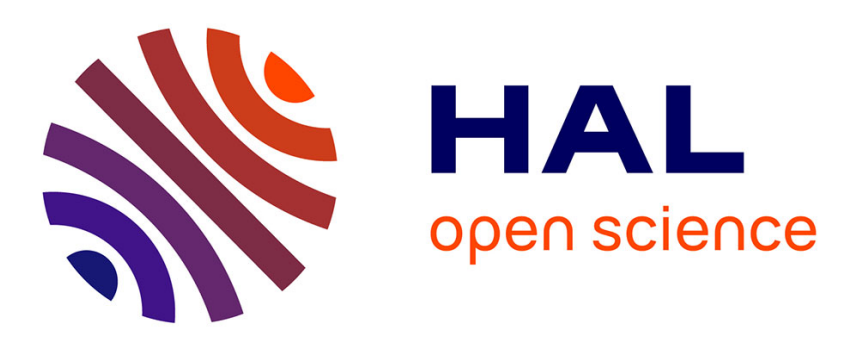

\title{
Basinga: A cell-by-cell GIS toolbox for computing basin average scaling factors, cosmogenic production rates and denudation rates
}

Julien Charreau, Pierre-Henri Blard, Jena Zumaque, L.C.P. Martin, Tony Delobel, L. Szafran

\section{To cite this version:}

Julien Charreau, Pierre-Henri Blard, Jena Zumaque, L.C.P. Martin, Tony Delobel, et al.. Basinga: A cell-by-cell GIS toolbox for computing basin average scaling factors, cosmogenic production rates and denudation rates. Earth Surface Processes and Landforms, 2019, 44 (12), pp.2349-2365. 10.1002/esp.4649 . hal-02377535

\section{HAL Id: hal-02377535 \\ https://hal.science/hal-02377535}

Submitted on 4 Jan 2021

HAL is a multi-disciplinary open access archive for the deposit and dissemination of scientific research documents, whether they are published or not. The documents may come from teaching and research institutions in France or abroad, or from public or private research centers.
L'archive ouverte pluridisciplinaire HAL, est destinée au dépôt et à la diffusion de documents scientifiques de niveau recherche, publiés ou non, émanant des établissements d'enseignement et de recherche français ou étrangers, des laboratoires publics ou privés. 


\section{Earth Surface Processes and Landforms BSG}

\section{BASINGA: a cell-by-cell GIS toolbox for computing BASIN averaGe scaling factors, cosmogenic production rates and denudation rAtes}

\begin{tabular}{|r|l|}
\hline Journal: & Earth Surface Processes and Landforms \\
\hline Manuscript ID & ESP-18-0325.R1 \\
\hline Wiley - Manuscript type: & Research Article \\
\hline Author: & n/a \\
\hline Complete List of Authors: & $\begin{array}{l}\text { CHARREAU, Julien; Université de Lorraine, CRPG } \\
\text { Blard, Pierre-Henri; Université de Lorraine, CRPG } \\
\text { Zumaque, Jéna; Universite du Quebec a Montreal Geotop, Geotop } \\
\text { Martin, Léo; University of Oslo, Department of Geosciences } \\
\text { Delobel, Tony; Université de Lorraine, CRPG } \\
\text { Szafran, Lucas; Université de Lorraine, CRPG }\end{array}$ \\
\hline Keywords: & $\begin{array}{l}\text { Scaling factors, Cosmogenic production rates, Basin average denudation } \\
\text { rates, ArcGIS and QGIS }\end{array}$ \\
\hline
\end{tabular}

\section{SCHOLARONE Manuscripts}




\section{BASINGA: a cell-by-cell GIS toolbox for computing BASIN averaGe scaling factors,} cosmogenic production rates and denudation rAtes

Julien Charreau $^{1 * *}$, Pierre-Henri Blard ${ }^{1}$, Jéna Zumaque ${ }^{1,2}$, Léo C.P. Martin ${ }^{1,3}$, Tony Delobel ${ }^{1}$ and Lucas Szafran ${ }^{1}$

1. CRPG, UMR 7358, CNRS, Université de Lorraine, 54501 Vandoeuvre-lès-Nancy, France, charreau@univlorraine.frr, blard@univ-lorraine.fr, tony-delobel@laposte.net, lucas.szafran@gmail.com

2. Geotop, Université de Québec à Montréal, CP 8888, Succ. Centre Ville Montréal, Québec, Canada, zumaque.jena@courrier.uqam.ca

3. Department of Geosciences, University of Oslo, P.O. Box 1047, Blindern, 0316 Oslo, Norway, leo.martin@geo.uio.no

${ }^{* *}$ corresponding author: Julien Charreau (charreau@crpg.cnrs-nancy.fr)

\section{Abstract}

The calculation of denudation rates from the measured cosmogenic nuclide concentrations in river sediments requires assumptions and approximations. Several different approaches and numerical tools are available in the literature. A widely used analytical approach represents the muogenic production with one or two exponentials, assumes the attenuation length of muons to be constant and also neglects temporal variations in the Earth magnetic field. The denudation rates are then directly and analytically calculated from the measured concentrations. A second numerical and iterative approach was more recently proposed and considers a more rigorous muogenic production laws based on pre-calculated variable attenuation length of muons and accounts for temporal changes of the magnetic field. It also assumes a specific distribution of denudation rates throughout the basin and uses an iterative approach to calculate the basin average denudation rates.

We tested the two approaches across several natural basins and we found that both approaches provide similar denudation results. Hence, assuming exponential muogenic production and constant attenuation length of muons in the rock has little impact on the derived denudation rates. Therefore, unless a priori known distributions of denudation rates are to be tested, there does not appear to be any particular gain from using the second iterative method which is computationally less effective. 
Based on these findings, we developed and describe here Basinga, a new ArcGIS ${ }^{\circledR}$ and

QGIS toolbox which computes the basin average scaling factors, cosmogenic production rates and denudation rates for several tens of drainage basins together. Basinga follows either the Lal/Stone or the LSD scaling schemes and includes several optional tools for correcting for topographic shielding, ice cover and lithology. We have also developed an original method for correcting the cosmogenic production rates for past variations in the Earth's magnetic field.

key words: scaling factors, cosmogenic production rates, denudation rates, ArcGIS and QGIS

\section{Introduction}

Denudation is a critical parameter controlling the landscape evolution. It can be determined at the scale of an entire watershed from the cosmogenic nuclides concentration measured in one river sediment sample (e.g. Brown et al., 1995). This method has consequently been widely used in a variety of geological settings (Portenga and Bierman, 2011). The calculation of denudation rates from measured concentrations in sediments relies on specific assumptions and requires computation of several parameters, notably the cosmogenic production rates at the surface of the drainage basin. The physical characteristics of these production rates can be estimated from a number of analytical, empirical or physical formulations. Consequently, in the literature, the approaches adopted vary between authors and studies, leading to potential discrepancies (Table 1) (e.g. Brown et al., 1995; Fox et al., 2015; Godard et al., 2012; Lupker et al., 2012; Mudd et al., 2016; Portenga and Bierman, 2011; Scherler et al., 2014). In this paper, we first review the different approaches, the associated assumptions and the formulae used to calculate the basin average denudation rates, and we test their sensitivity. From these results, we define a strategy to estimate the true basin average denudation rates and find the best balance between the computational time of the methods and their accuracy. Accordingly, we have developed and present here a free, simple and open-source tool that provides an accurate and efficient means for computing the basin average denudation rates under different assumptions and scaling models. It is named Basinga (BASIN-averaGe scaling factors, cosmogenic production and denudation rAtes) and includes two Python-script-based geoprocessing tools that 
63 simple and user-friendly graphical interfaces that can be installed and run on two widely used 64 GIS systems: ArcGIS $\AA$ and QGIS.

\section{Denudation rates from the cosmogenic concentration}

\subsection{General formulation}

At any location, the concentration $\mathrm{N}\left(\right.$ atoms $^{-1} \mathrm{~g}^{-1}$ ) of a cosmogenic nuclide $\boldsymbol{i}$ in a surface rock $(\mathrm{z}=0)$ can be related to the exposure duration $\boldsymbol{t}(\mathrm{a})$ (present is 0 and positive toward the past) and the local denudation rate $\varepsilon\left(\mathrm{cm}^{-\mathrm{a}^{-1}}\right)$ following this general equation (e.g. Balco, 2017):

$$
N_{z=0, i}=\sum_{x=s p, \mu} \int_{0}^{\infty} P_{x, i}(\varepsilon t) e^{-\lambda_{i} t} d t
$$

where the subscript $\boldsymbol{i}$ and $\boldsymbol{x}$ indicate the studied cosmogenic nuclide (e.g. ${ }^{10} \mathrm{Be},{ }^{26} \mathrm{Al},{ }^{3} \mathrm{He},{ }^{21} \mathrm{Ne}$ ) and the cosmogenic production pathway ( $s p$ for production by spallation; $\mu$ for slow muon capture and fast muon processes), respectively. $\lambda_{i}$ is the decay constant of the studied nuclide $\left(4.9975 \times 10^{-7} \mathrm{a}^{-1}\right.$ for ${ }^{10} \mathrm{Be}$; (Chmeleff et al., 2010)). $P_{x, i}$, is the local in situ cosmogenic production rates at the surface $\left(\right.$ at. $\left.^{-1} \cdot \mathrm{a}^{-1}\right)$ of the production mechanism associated with each pathway $\boldsymbol{x}$. The depth production due to spallation follows an exponential (Lal, 1991), then the equation (1) can

78 be rewritten as follow:

$$
N_{z=0, i}=\frac{P_{s p, i}}{\frac{\rho \varepsilon}{\Lambda_{s p, i}}+\lambda_{i}} e^{-\left(\frac{\rho \varepsilon}{\Lambda_{s p, i}}+\lambda_{i}\right) t}+\int_{0}^{\infty} P_{\mu, i}(\varepsilon t) e^{-\lambda_{i} t} d t
$$

where $\rho$ and $\Lambda_{s p, i}$ are the rock density $\left(\mathrm{g} \mathrm{cm}^{-3}\right)$ and the attenuation length of fast neutron production $\left(\mathrm{g} . \mathrm{cm}^{-2}\right)$, respectively. This later theoretically varies with latitude and elevation, and more specifically with atmospheric depth and cut-off rigidity (Gosse and Phillips, 2001; Lal, 1991; Marrero et al., 2015; Sato et al., 2008; Stone, 2000). It is however difficult to constrain with accuracy, and therefore it is often convenient to assume a constant value of $160 \mathrm{~g} . \mathrm{cm}^{-2}$ for $\Lambda_{s p, i}$ (e.g. Braucher et al., 2011).

The first term of this equation (2) that represents the spallogenic production is generally simplified in $\frac{P_{s p, i}}{\frac{\rho \varepsilon}{\Lambda_{s p, i}}+\lambda_{i}}$, assuming that there is no inherited cosmogenic nuclide before exposure initiation and that the cosmogenic nuclide concentration has reached steady state (i.e. $t>>1 /(\lambda+$ $\varepsilon \rho / \Lambda$ ) (Brown et al., 1995; Lal, 1991). In some conditions, the denudation may not be at steady state and hence the denudation rates derived from this assumption can be biased (e.g. Bierman and Steig, 1996). However, the potential inaccuracy due to the violation of this assumption is 
92 significant (30 to $50 \%)$ only in very slowly eroding landscapes $\left(<10^{-3} \mathrm{~cm} / \mathrm{a}\right)$ but remain below 93 few percent in most of the other geological contexts (Bierman and Steig, 1996; Schaller and 94 Ehlers, 2006).

The second term of equation (2) represents the muogenic contribution, which includes two 96 different production pathways (slow muon capture and fast muon processes). Rigorously, the depth-dependence production rates of these particles do not follow a simple exponential attenuation (Heisinger et al., 2002a, 2002b). Equation (2) should include a rigorous calculation of the muogenic contribution following the Heisinger's equations (Heisinger et al., 2002a, 2002b) (see for example equations 5 and 6 in Balco, 2017).

Assuming that a river mixes the sediments eroded across the whole drainage basin well, the concentration measured at the river outlet represents the basin average of all local concentrations (Brown et al., 1995; Lal, 1991). By solving and integrating equation (2) over the basin surface, it is therefore possible to derive the average denudation rate at the basin scale from a measured cosmogenic nuclide concentration in a river sediment (Brown et al., 1995; Lal, 1991), provided that the cosmogenic production rates of the nuclide at the surface $\left(P_{x, i}\right)$ are known at each point of the basin.

108

\subsection{The cosmogenic production rates and scaling factors}

The in situ spallogenic production of cosmogenic nuclides at the surface is a function of 111 the longitude, but more importantly of the latitude $\boldsymbol{L}\left({ }^{\circ}\right)$, since it is primarily controlled by the 112 quantity of cosmic flux that reaches the high atmosphere and is therefore driven by the strength 113 of the geomagnetic field and the cut-off rigidity of the incoming particles (Lal, 1991). Moreover, 114 temporal variations in the Earth's magnetic field (e.g. Valet et al., 2005) are responsible for 115 changes in the cosmic flux (Dunai, 2001; Nishiizumi et al., 1989; Pigati and Lifton, 2004) and 116 hence in the spallogenic production rates. The cosmogenic nuclide concentration measured at the 117 surface is integrated over an equivalent exposure time, which-represents the time needed by the 118 grain to reach the surface while it is subjected to cosmic ray bombardment. This duration depends 119 on the denudation rate and the attenuation length: $t_{\mathrm{eq}}=1 /(\lambda+\rho \varepsilon / \Lambda)$. However, the Earth's 120 magnetic field has negligible impact on muon fluxes and hence on muogenic production (e.g. 121 Balco et al., 2008; Braucher et al., 2011; Lifton et al., 2014). Both production pathways are a 122 function of the elevation since the secondary fluxes produced in the high atmosphere are 
123 attenuated both in flux and energy by the atmosphere ( $\mathrm{Lal}, 1991)$. In the calculations, elevation is 124 usually converted to the equivalent atmospheric depth $\boldsymbol{h}\left(\mathrm{g} . \mathrm{cm}^{-2}\right)$ (Stone, 2000), which can be 125 calculated either using the hydrostatic standard atmosphere model specific to mid-latitude and the northern hemisphere (see Equation (1) in Stone (2000)) or can been interpolated from the atmospheric 2D ERA-40 database (Uppala et al., 2005).

The rate of cosmogenic production at the surface $\left(\mathrm{at}^{\mathrm{g}} \mathrm{g}^{-1} \cdot \mathrm{a}^{-1}\right)$ at any location within a given watershed can be scaled to the latitude, elevation and time as follows:

$$
P_{i, x}=P_{i, x, S L H L} \cdot S_{i, x}(h, L, t(\varepsilon))
$$

131 where $P_{i, x, S L H L}$ is the surface production at Sea Level and High Latitude (SLHL) (at. $\mathrm{g}^{-1} \cdot \mathrm{a}^{-1}$ ) for 132 each nuclide $i$ and production pathway $x$. Global average values for the SLHL production rates of 133 different nuclides have recently been constrained by Martin et al. (2017) (see table 7), taking into 134 account all published calibration studies, notably the most recent ones (Balco et al., 2009; 135 Kaplan et al., 2011; Kelly et al., 2015; Lifton et al., 2014; Martin et al., 2015; Stroeven et al., 136 2015). These worldwide averages were computed using the CREp program (Martin et al., 2017) 137 and include a time-integration correction based on the VDM reconstructed by Muscheler et al. 138 (2005).

139 In equation (3), $\mathrm{S}_{\mathrm{i}, \mathrm{x}}$ represents the scaling factor for each production pathway $\mathrm{x}$ and each 140 studied nuclide i. Several empirical scaling models have been proposed in the literature. Some of 141 them were calibrated from the counting of spallation events by either photo-emulsion (e.g. Lal, 142 1991; Stone, 2000) or neutron-monitor (Desilets et al., 2006; Dunai, 2001; Lifton et al., 2005). 143 However, more recently, a purely theoretical and physical ab initio model was developed by 144 Lifton/Sato/Dunai (LSD) to describe the temporal and spatial variability in cosmogenic 145 production (Lifton et al., 2014).

146 For computational efficiency, previous studies (e.g. Fox et al., 2015; Godard et al., 2014; 147 Scherler et al., 2014; Wittmann and von Blanckenburg, 2009) have often calculated the 148 production rates using the widely used and accessible empirical scaling scheme of Lal/Stone (Lal, 149 1991; Stone, 2000). Considering the worldwide calibration dataset, statistical analyses show that 150 the Lal/Stone model has a better accuracy than the neutron-monitor-based schemes (Balco, 2017; 151 Borchers et al., 2015; Phillips et al., 2016). These analyses also show that, despite regional 152 differences, the Lal/Stone model has a similar efficiency than the LSD model (Borchers et al., 153 2015; Lifton et al., 2014). 
However, calibration sites remain too sparse to accurately unravel the full differences between these two models at the global scale (Figs. 1 and 2). To estimate the spatial variability and the agreement between the two models, we calculated the difference between the two scaling models for the entire world, using as inputs the 2D ERA atmosphere database (Uppala et al., 2005) and the Global Multi-resolution Terrain Elevation Data 2010 (GMTED2010) (Danielson and Gesch, 2011). In most regions the two models differ by less than $10 \%$ on average, especially at mid-latitude and moderate elevation (1-4 km) (Figs. 1 and 2). At high altitude/high latitude and low altitude/low latitude the discrepancy between the two models may reach $\sim 20-30 \%$ (Figs. 1 and 2) (Phillips et al., 2016). The difference also varies strongly with altitude (Fig. 1).

\section{Approaches and assumptions for computing basin average denudation rates}

The equations (1) and (2), that link the denudation rate to the cosmogenic concentration at the surface, are rigorously implicit in $\varepsilon$. To calculate the basin average denudation rate from the cosmogenic concentration measured at the outlet, assumptions and approximations must therefore be made and two sorts of approach (analytical or numerical) have been developed for this (Table 1) (Balco et al., 2008; Brown et al., 1995; Mudd et al., 2016).

\subsection{Analytical approaches}

The first type of approach, which are traditionally used in the literature, either neglects the muogenic production (method 1 in Table 1) or approximates, similarly to the spallogenic production, the two muogenic production rates at depth with either one or two different exponential laws (methods 2 and 3 in Table 1) (e.g. Braucher et al., 2011; Lupker et al., 2012). 176 Then, the equation (2) can be simplified as follow:

$$
N_{Z=0, i}=\sum_{x=s p, \mu_{s m}, \mu_{f m}} \frac{P_{x, i}}{\frac{\rho \varepsilon}{\Lambda_{x, i}}+\lambda_{i}}
$$

178 where $\mu_{s m}$ and $\mu_{f m}$ indicate the two muogenic production pathways. This approach may use the 179 constant attenuation lengths of $4320 \mathrm{~g} / \mathrm{cm}^{2}$ and $1500 \mathrm{~g} / \mathrm{cm}^{2}$ determined by Braucher et al. (2011) 180 using the experimental data of Heisinger et al. (2002a,b) for fast muons capture and slow muons 181 processes, respectively (method 2). If only one family of muons is considered with a single 182 exponential then one single constant attenuation length in the rocks can be used (method 3) (see 183 table 2 in Braucher et al., 2013). 
This first type of approach (methods 1,2 and 3) also assumes no temporal variation in the Earth's magnetic field. In such a case, equation (4) can be directly solved analytically (Brown et al., 1995). The basin average denudation rate is only a function of the concentration measured at the outlet and the present average cosmogenic production rate of the basin (e.g. Brown et al., 1995). In the literature, the latter is sometimes estimated from the mean altitude and latitude of the studied catchment area (method 1) (Brown et al., 1995). However, because the production rate vs. elevation relationship is non-linear, such an approximation may induce significant uncertainties ( $>30 \%)$, especially in high elevation regions with high relief in the drainage basins. To avoid these inaccuracies, it is critical to consider the whole basin topography (Balco et al., 2008). A more accurate method scales the factors and hence the production rates on a pixel basis using a Digital Elevation Model (DEM) and a cell-by-cell approach (methods 2 and 3) (e.g. Fox et al., 2015; Godard et al., 2012; Lupker et al., 2012). The average production at the basin scale

\section{$\underline{3.2 \text { Iterative numerical approaches }}$}

The second type of approach solves the equation (2) numerically in order to provide the 200 denudation rates (e.g. Balco et al., 2008) (methods 4,5 and 6 in Table 1). Indeed, based on this 201 equation and using the Heisinger's formulation of the muogenic production (Heisinger et al., 2002a, 2002b), it is possible to compute a theoretical cosmogenic concentration only if the denudation is a priori known. Then, the denudation rate can be adjusted iteratively in order to minimize the discrepancy between the measured and calculated concentrations (method 4). This iterative methodology is available in the updated online calculator of Balco et al. (2008) (http://hess.ess.washington.edu/). One advantage of this method is that the exposure duration can be calculated from the input denudation at each iteration and, thus, the cosmogenic production rate can be corrected for temporal variations in the Earth's magnetic field (Balco et al., 2008). However, the initial code of Balco et al. (2008) was designed for the calculation of local denudation rates only (method 4).

To extrapolate this iterative technique at the basin scale one must assume that the denudation is homogenous (Mudd et al., 2016; Scherler et al., 2014) or specify a known distribution of denudation throughout the basin. Otherwise, there would be an infinite number of denudation distribution solutions throughout the basin that could be possible. Based on this $a$ 
215 priori known denudation distribution (homogenous or specified) the production rates can be 216 corrected for temporal variations in the Earth's magnetic field. Again, as for the previous 217 approaches (methods 1,2 and 3), this method requires calculation of the cosmogenic production 218 rates for both production pathways (spallogenic and muogenic) at each location in the basin, and 219 this must also be made on a pixel basis using a DEM. The concentration of a cosmogenic nuclide 220 at each location and the basin average concentration could then be calculated accordingly. The 221 denudation rate of the basin could then be adjusted iteratively in order to minimize the 222 discrepancy between the measured and calculated concentrations at the outlet. To use this 223 iterative methodology at the basin scale one would need to calculate the muogenic production 224 using Heisinger's equations at each point of the basin, which is a time-consuming computation. 225 Therefore, such an approach still needs to be fully developed for the calculation of basin average 226 denudation rates. Indeed, though Mudd et al. (2016) have developed an iterative methodology, 227 they assumed a constant attenuation length for muons and considered only present-day 228 production rates derived from the Lal/Stone model, without any correction for temporal 229 variations (method 5 in Table 1).

230 Alternatively, the right muogenic production can be calculated using Heisinger's 231 formulations (Heisinger et al., 2002a, 2002b) for a reasonable range of denudation rates and 232 atmospheric depth values and, hence, the attenuation length of muons can be derived accordingly 233 assuming a single exponential law (see equation 12 of Balco, 2017) (Fig. 3). Based on these pre234 calculated values, the attenuation length of muons can be interpolated at each point of a given 235 drainage basin using elevations and denudations grids. The cosmogenic concentration can be then 236 more quickly but relatively accurately estimated at each point of the studied basin. The denudation 237 rate can be then derived using the same iterative technic than in method 4 and 5 (method 6).

\section{Sensitivity analysis}

It is worth testing and comparing the accuracies of the two types of approach. Moreover, 241 it is still unclear if the new LSD model would yield any significant differences when calculating 242 basin average denudation rates.

\subsection{Approach}


To discriminate between the two types of approach and the two scaling models, we considered several natural catchments across the world, notably in regions where the two scaling 247 schemes differ strongly (Table 2), in particular at high latitude/high elevation (i.e. the Susitna basin in Alaska) and at low latitude/low elevation (the Maroni basin in the French Guyana, 0$900 \mathrm{~m}$ at $\sim 4^{\circ} \mathrm{N}$ ) (Fig. 1). We also tested several basins that exhibit a wide elevation range (i.e. 250 Marshyangdi, Kuitun). At each cell in a basin, we assumed that denudation was a linear function 251 of the local slope. We then arbitrarily set the maximum denudation rate so that the basin average 252 denudation rate roughly equaled the rates reported in the literature, which were derived from 253 thermochronology, sediment gauging and/or TCN analysis (see the complete list of references 254 given in Table 2) (Fig. 4).

Based on these a priori known denudation rate distributions, we applied a forward model 256 to calculate the theoretical "true" in situ ${ }^{10} \mathrm{Be}$ concentrations at each cell in the basins. We used 257 both the LSD (Lifton, 2015) and Lal/Stone (Lal, 1991; Stone, 2000) schemes to estimate the 258 scaling factors and production rates in each cell based on the cell's latitude, longitude and 259 elevation. For the LSD model, we used the Matlab ${ }^{\circledR}$ functions of Lifton et al. (2015), which were 260 amended by Martin et al. (2017) to test for different dipolar geomagnetic corrections. When using 261 the Lal/Stone scheme the time was not integrated and we used only the present-day scaling 262 factors. For LSD, we considered both the present-day factors and factors corrected for variations 263 in the Earth's magnetic field. In such a case, the time was integrated for each cell based on the 264 equivalent time derived from the denudation itself. Atmospheric depth was always calculated 265 using the data from the 2D ERA-40 database (Uppala et al., 2005). ${ }^{10} \mathrm{Be}$ cosmogenic production 266 rates were calculated based on the SLHL rate of 4.11 of Martin et al. (2017) (see their Table 7). 267 We followed the approach and database proposed by Balco (2017) to accurately estimate the 268 attenuation length of muons in the rocks as a function of the denudation and elevation (Fig. 4). 269 Next, we calculated the basin average "true" concentration using equation (4). These values were 270 then inverted using the two types of approach (method 3 vs. 5) to estimate the basin average 271 denudation rates for each basin accordingly. For consistency, the inversions considered the same 272 scaling as that used during the calculation of the theoretical concentration. For the iterative 273 approach, the distribution of the denudation was assumed to be homogenous throughout the 274 basin. Since the attenuation length of muons as a function of denudation and elevation can only 275 be calculated for all muons together, in the analytical approach we therefore considered only one 
276 single family of muons and used the method 3 with constant attenuation length in the rocks. We 277 used the value of $4814 \mathrm{~g} . \mathrm{cm}^{-2}$ which represents the mean of the attenuation lengths given in 278 Braucher et al. (2013). Finally, we compared the inverted average denudation results to the input 279 theoretical values.

\section{$\underline{4.2 \text { Results }}$}

The complete results are given in table 2 and figures 5, 6 and 7 show the results for 283 representative basins. For most of the studied basins, we found that the analytical approach 284 (method 3) (which assumes the attenuation length of muons to be constant) provided denudation 285 rate estimates that were on average better than or similar to those of the iterative approach, 286 whatever the scaling model used. Adding the temporal modulation of the production rates led to 287 larger misfits between the denudation rates calculated using the analytical approach (which uses 288 the present rates) and the theoretical denudation rates. However, the iterative approach, which 289 can account for these modulations, did not provide better results (Table 2) and for several basins 290 it yielded large differences (10-20\%)(Fig. 5). When we used the scaling models for inversion 291 without time integration ahead, meaning that only the attenuation length of muons differed 292 between the theoretical calculation and the inversion, the differences between the theoretical and 293 inverted denudation rates were on average negligible except for basins with very low denudation 294 rates (i.e. Maroni and Chambal), where the differences were significant $(<10 \%)$.

\section{Discussion and implementation in Basinga}

\section{$\underline{5.1 \text { Goals of Basinga }}$}

The first aim of Basinga (BASIN-averaGe scaling factors, cosmogenic production and denudation rAtes) was to provide a tool, named "Production rate", for computing cosmogenic 300 production rates for different nuclides $\left({ }^{3} \mathrm{He},{ }^{21} \mathrm{Ne}\right.$ and $\left.{ }^{10} \mathrm{Be}\right)$. The second goal of Basinga was to calculate, for a large number of drainage basins together, the mean denudation rates from the cosmogenic concentrations measured at their outlet. Hence, a second tool named "Denudation rates" was designed. Our main objective was to provide, for both tools, simple and user-friendly graphical interfaces that could be installed on GIS systems and run using simple Digital Elevation Model (DEM) raster and shape files of the drainage basins. Based on the above methodological 306 analysis, we therefore developed Python-script-based geoprocessing tools that can be run and 
307

308

309

310

311

312

313

314

315

316

317

318

319

320

321

322

323

324

325

326

327

328

329

330

331

332

333

334

335

336

337

installed on two widely used and/or free GIS systems, ArcGIS ${ }^{\circledR}$ and QGIS. These tools calculate the cosmogenic production and denudation rates for several nuclides, based on two possible scaling models and using several corrective options that were built to improve the accuracy of the estimates. However, all of these methodological improvements and associated potential gain in accuracy must be handled with caution, given the uncertainties associated to the cosmogenic method itself, especially in low eroding landscape $(<0.001 \mathrm{~cm} / \mathrm{a})$ (Bierman and Steig, 1996). A detailed description of Basinga, its interfaces and how they can be used are given in the Supplementary information.

\subsection{Choice of the scaling model}

At moderate altitudes (1000-6000m), the differences between the two scaling models are in general quite low $(<10 \%)$. Hence, for basins of high relief at moderate elevation (e.g. Marshyangdi, Susitna, Kuitun), the weights of the extreme scaling values are likely negligible and the higher production rates at lower elevations derived using Lal/Stone are compensated for by the lower production rates at high elevation (Figs. 6 and 7). Moreover, the true difference between the two scaling models is likely lower than our modeling suggests because at high elevation, where the discrepancies between the models are greater, cosmogenic production is partially canceled out by ice cover that shields surficial rocks from cosmic rays. The other sources of random uncertainty associated with the cosmogenic measurements are equivalent to the bias computed in our simulation (ca. 5 to 10\%). Therefore, given the other geological uncertainties such as those related to the steady state assumption (Bierman and Steig, 1996; Schaller and Ehlers, 2006), for most natural cases, the choice of the scaling model will have little impact. Since it is computationally more efficient to follow the Lal/Stone model for calculating the cosmogenic production rates, we would encourage use of this model in most of the cases.

Nevertheless, precautions must be taken when studying drainage basins or sub-catchments of low relief in regions where the difference between the two scaling models is rather high (15$30 \%)$. For example, in the Maroni and Chambal basins, because of the low relief (0-1000m) and low latitude, the difference between the scaling models is significant everywhere and the extreme values are not compensated by each other. The resulting difference in denudation rates remains significant $(\sim 15 \%)$. Unfortunately, the calibration data remain too sparse in these particular regions to determine which of the two models is more accurate (Phillips et al., 2016; Martin et al., 
338 2017). In such cases, and until new discriminant calibration data are provided, both scaling 339 models should be used to provide a realistic range of possible denudation values. However, if the 340 expected denudation rates of the studied low relief region are low $(<0.001 \mathrm{~cm} / \mathrm{a})$, the difference 341 between the two estimates will likely be in the range of the uncertainties associated to the 342 precision of the cosmogenic method itself (Bierman and Steig, 1996).

343 The Basinga tool Production rates thus allows the user to calculate the scaling factors and 344 the production rates using either the LSD or the Lal/stone model. The LSD model was 345 implemented in Python using the Matlab functions of Lifton et al. (2014) modified by Martin et 346 al. (2017). The Production rates tool calculates the basin average production rates based on the 347 SLHL rates provided in Martin et al. (2017) (see their table 7) as a function of the studied nuclide 348 and the scaling model and derived from the ERA40 atmosphere database. For ${ }^{21}$ Ne the SLHL is 349 calculated from the ${ }^{10} \mathrm{Be}$ SLHL rate and a ${ }^{10} \mathrm{Be} /{ }^{21} \mathrm{Ne}$ ratio of 4.12 (Kober et al., 2011). The SLHL 350 for each particles are calculated based on their relative production rate to the total production at 351 sea level high latitude with values of $98.86 \%, 0.27 \%$ and $0.87 \%$ for spallation, slow muon 352 capture and fast muon processes, respectively (see table Table 1 of Martin et al., 2017 and 353 Braucher et al., 2011).

354 Nevertheless, the SLHL values can be easily updated and modified in the program file if 355 needed using a simple text editor (see Online supplementary information and the section "Getting 356 Started" for the procedure and which lines to change). For example, local or regional SLHL 357 values can be used, as derived from the CREp program and using a compilation of local 358 calibration sites (Martin et al., 2017).

359 However, calculation of the production rates using LSD may take several hours for an 360 average sized drainage basin of few thousand $\mathrm{km}^{2}$ (Fig. 8). For large catchments, for example the 361 Gangese $\left(9.0 \times 10^{5} \mathrm{~km}^{2}\right)$, the Amazon $\left(6.9 \times 10^{6} \mathrm{~km}^{2}\right)$ or the Rhône $\left(9.7 \times 10^{4} \mathrm{~km}^{2}\right)$, the computing 362 time can be very long (Fig. 8) and the computation may be difficult to perform on a simple laptop 363 computer. The same is true if a large number of basins are analyzed together. In such cases, the 364 resolution of the analyzed DEM needs to be increased, which could generate a potential source of 365 inaccuracy. Use of the LSD model is therefore for now limited to basins of small size. 
To overcome this issue and to reduce the computing time when using the LSD model, we can lean on the simple relationship that exists, at the basin scale, between the Lal/Stone and the 370 LSD scaling factors (Figs. 2, 6 and 7). If time is not integrated to correct for past changes in the 371 Earth's magnetic field, the relationship between the two models can be approximated by a simple 372 polynomial law for each basin (Figs. 6 and 7). The spallogenic and muogenic factors for both 373 models can be calculated together over a small number of cells that are randomly sampled within 374 the studied basin. These data can then be used to find the best fit relationship between the two 375 models for each production pathway. The LSD factors on the other cells are then calculated using these conversion laws and the previous Lal/Stone factors that had been quickly estimated for each cell. Our tests show that a 4 degree polynomial fit derived from 1000 sampled cells provides an accurate law for estimating the LSD factors of the whole basin (the average bias is lower than $1 \%$, and never exceeds 3\%) (Fig. 9). This alternative approach significantly reduces the computing time needed to calculate the LSD scaling factors when time is not integrated (Fig. 8). A similar approximation of the LSD factors based on a pre-calculated table is also used in the updated online calculator of Balco et al. (2008) (http://hess.ess.washington.edu/). When using the LSD model in Basinga, this simplification can be activated if desired.

\section{$\underline{5.4 \text { Chosen methodology for denudation inversion }}$}

Though we analyzed ten natural basins in different settings, because the controlling factors are multiple (denudation, hypsometry, reliefs, latitude, longitude etc) our results cannot easily be generalized. Since the calculations are relatively long for each basin, especially when using the iterative approach, it is difficult to multiply the studied cases to encompass all possible variations in all of these factors. To discriminate between the two methods, the net influence of the attenuation length of muons in the rocks is critical. However, the sensitivity of the denudation rate to this parameter can be tested more systematically using the Lal/Stone model, which is computationally more efficient. In such a case, it is computationally possible to vary the maximum altitude (hence its relief), the mean latitude and the denudation distribution of a given basin of relatively small size. We considered here a smaller sub-basin of the Marshyangdi and fixed its hypsometry while the other parameters were varied. We tested about 300 different cases with mean latitudes, reliefs and denudation rates ranging from $5^{\circ}$ to $55^{\circ}, 450$ to $4500 \mathrm{~m}$ and 0.01 to $0.4 \mathrm{~cm} / \mathrm{a}$, respectively. The differences between the inverted and theoretical denudation are on 
399 average less than 1\% (Fig. 10). These results also suggest that assuming a constant attenuation 400 length of $4814 \mathrm{~g} . \mathrm{cm}^{-2}$ (Braucher et al., 2013) has negligible impact on the final denudation results 401 in a wide range of settings. However, for very low denudation rates $(<0.01 \mathrm{~cm} / \mathrm{a})$ at low altitude $402(<1000 \mathrm{~m})$, as for example in the Maroni and Chambal basins, the effective attenuation length 403 derived by Balco (2017) is significantly lower than Braucher's value (Fig. 1), resulting in larger 404 discrepancies between theoretical and inverted denudation rates. The discrepancy still remains 405 lower than $<10 \%$ however (Fig. 10). These results reinforce the conclusion that the analytical 406 approach provides relatively accurate results even if variations in the attenuation length of muons 407 are neglected.

408 Moreover, the analytical approach has the advantage of being straightforward and 409 computationally faster even when using the LSD model. In contrast, the numerical and iterative 410 approach requires, at each step, the attenuation length of muons from the tested denudation to be 411 re-computed for each cell. If the temporal fluctuations in the production rates are integrated, the 412 associated computation must also be performed at each step as function of the tested denudation 413 rates. The time needed to compute the scaling factors is hence significantly increased and the 414 calculation may take several tens of hours for a basin of average size when using the time415 dependent version of the LSD model (Fig. 8).

416 At last, the potential gain in accuracy that could results from considering variations in the 417 attenuation length of muons is likely negligible compared to the natural geological uncertainties.

418 Nevertheless, the iterative approach merits consideration if an a priori known distribution 419 of denudation is available, derived for example from shear stress, lithology data or output from 420 numerical landscape models. In such a case, the tool developed by Mudd et al. (2016), which is 421 freely available online, may be used. However, this tool is based on the Lal/stone model only and 422 also assumes a constant attenuation length of muons. A complete iterative tool, with a variable 423 attenuation length of muons and based on the LSD model including time integration, has yet to be 424 developed.

425 If the distribution of denudation is a priori unknown, the use of the analytical approach is, 426 in our opinion, sufficient and more efficient. Unfortunately, no simple and freely available tool 427 has been provided for this approach. Consequently, our second Python script, Denudation rates, 428 follows the analytical approach and uses the method 2 (Table 1) with the muogenic production 429 represented by two exponentials. To calculate the denudation rates for each basin studied, 
430 Denudation rates requires the measured concentration of the in situ cosmogenic nuclide at the 431 outlet and the calculation of the basin average production rates before. These basin averages are 432 provided by the Production rates tool using a DEM projected in a geographical system with the 433 area of each individual cells of the DEM corrected for latitudinal effects.

5.5 An approach for integrating time and changes in the Earth's magnetic field using the 436 analytical approach

437 Theoretically, the analytical approach precludes any accounting for past changes in the 438 Earth's magnetic field because the production rates are calculated for the present time only. In 439 many mountain ranges, such as in Taiwan, the Himalayas or the New Zealand Alps, denudation 440 rates are usually high and exceed 0.1-0.2 cm/a (Derrieux et al., 2014; Herman et al., 2010; 441 Lupker et al., 2012). In such cases, the equivalent exposure times are low ( $<400$ a) and the 442 associated biases likely negligible (Fig. 11). However, for regions of lower denudation, such as in 443 the Tianshan mountains (i.e $<0.05 \mathrm{~cm} / \mathrm{a})$ (e.g. Charreau et al., 2011), where typical equivalent 444 exposure times are on the order of several ka, ignoring changes in the Earth's magnetic field may 445 induce biases of up to 20\% (e.g. Lifton, 2016; Martin et al., 2016) (Fig. 11). Such biases are 446 significantly higher than the potential errors associated to the geological uncertainties, especially 447 than those associated to the violation of the steady state assumption (Bierman and Steig, 1996; 448 Schaller and Ehlers, 2006). If overlooked, this may lead to significant inaccuracies in the derived 449 denudation rates.

450 Temporal variations in the Earth magnetic field can be theoretically integrated using the 451 LSD model and the iterative approach. However, the inverted denudation rates still differ from 452 the theoretical values and are not significantly better than those derived from the analytical 453 approach without time integration (Table 2). Therefore, to account for the past changes in the 454 Earth's magnetic field when using the analytical approach (method 2) in Basinga, we have 455 developed a simplified approach. Based on equation 4, the equivalent exposure time at the basin 456 scale can be approximated by dividing the nuclide concentration measured at the outlet by the 457 basin average production rates calculated without paleomagnetic correction. The production rates 458 can then be corrected for the paleomagnetic changes by integration during this so-computed 459 equivalent exposure time. We followed the approach developed in the online CREp program 460 (Martin et al., 2017), where the fundamental equations of the Lal/Stone model have been 
461 modified to use the cut-off rigidity rather than the latitude (see paragraph 2.2 of Martin et al., 462 2017). Based on a Virtual Dipole Moment (VDM) database, the rigidity is integrated during the 463 equivalent exposure time and the new production rates calculated accordingly whatever the 464 scaling model used. During the calculation we consider only the Muscheler's VDM database 465 (Muscheler et al., 2005) as use of other VDMs would yield negligible differences $(<5 \%)$ 466 compared to the other random analytical uncertainties $(\sim 10 \%)$. In addition, the Muscheler 467 geomagnetic database is effective in reducing the dispersion in the data set of the world wide 468 SHLH production rates when coupled with the Lal/Stone or LSD model (Martin et al. 2017).

469 However, the integration time should in theory be different for each cell of the basin since 470 each is affected by a different denudation rate while equation 4 requires a uniform denudation 471 rate throughout the basin. This time correction is thus a simplification that may introduce some 472 bias. This approach can therefore only provide a first order estimate of the paleomagnetic 473 correction and must be handled with caution.

474

475

476

477

478

479

480

481

482

483

484

485

486

487

488

489

490

491

\subsection{Additional corrective options}

Basinga also includes several other corrections and options (see the Supplementary Information for a technical description of these options). First, several authors have highlighted the importance of the geometry of the exposed surface (e.g. Lal, 1991; Dunne et al., 1999; Gosse and Phillips, 2001). The quantity of the incoming cosmic ray flux received at a geographic point strongly depends on topographic shielding by both the surrounding relief and the local slope. An option was therefore built to correct for this topographic shielding. However, this optional correction must be used with caution. Indeed, DiBiase (2018) suggests that the topographic shielding correction is inappropriate in many settings. According to this author this correction is only needed for steep catchments with non-uniform distribution of quartz and/or erosion rate.

Second, the TCN approach assumes a uniform concentration of quartz throughout the catchment area which may bias the results toward the quartz-bearing locations. If instead the quartz content of eroded lithologies varies across the studied basin, equation (4) is no longer valid. However, though it remains relatively difficult to quantify the concentration of quartz from each eroded lithology, we can at least exclude any lithology without quartz from the calculation (e.g. Delunel et al., 2010). We therefore integrated and built an additional option that allows the corresponding area to be removed from the studied watershed. 
492

493

494

495

496

497

498

499

500

501

502

503

504

505

506

507

508

509

510

511

512

513

514

515

516

517

518

519

520

521

522

Third, the presence of an ice cap may shield the ground surface from incoming cosmic rays, thereby reducing or preventing cosmogenic in situ production. Basinga also allows a correction for ice cover when computing the scaling factor and cosmogenic production rate. We assume that the ice cover is sufficiently thick to fully shield the surface and thus that no cosmogenic isotopes are produced below the ice (Wittmann et al., 2007). However, because ice erosion remains efficient, the area covered by ice may still deliver sediment to the main stream (Wittmann et al., 2007). As they have previously been shielded by ice, in Basinga these sediments are presumed to be free of cosmogenic isotopes. However, in nature, processes of glacial erosion are far more complex, with notably, supra-glacial hillslopes providing sediments whose cosmogenic concentration may differ from 0 (e.g. Godard et al., 2012; Guillon et al., 2015). Moreover, the ice cover may have varied during time with periods of retreat and hence cosmic exposition and periods of advance and shielding. Accounting for all these glacial complexities in order to calculate more accurate denudation rates is likely vain. Therefore, the goal of this new option is not to improve the precision of the denudation rates but to provide endmember values of the denudation rates. Indeed, because glaciers are located at high elevations, assuming a zero production under the ice could result in an underestimation of production rates and thus an underestimation of the true denudation rates. Conversely, assuming full production by ignoring the ice cap would lead to overestimation of the production and denudation rates. The two scenarios can be easily tested using Basinga to bracket the true denudation rates.

Like glacial cover, snow cover can also partially shield the rocks and should be accounted for when estimating the production rates. This effect is particularly significant in high elevation mountain ranges, and may induce a reduction of the overall production rate by 5 to $10 \%$ (Scherler et al., 2014; Schildgen et al., 2005). Schildgen et al. (2005) attempted to correct for snow cover using a complex physical model coupled with remote sensing monitoring of snow cover spanning several years, which required calibration from ground-based records and measurements. Snow thickness can also be estimated from Precipitation Daily Data (PDD) derived from Global Climate Models (GCM). Such calculations are far beyond the goal of Basinga. However, this correction can be computed independently and integrated into Basinga by multiplying it by the topographic shielding factor. In such a case, the snow correction will be included in the overall calculation if the correction for topographic shielding is selected during the process. 


\subsection{Estimation of the denudation uncertainties}

Basinga also provides an estimation of the denudation uncertainties. However, errors in the cosmogenic production rates and the measured concentrations are only propagated as follows:

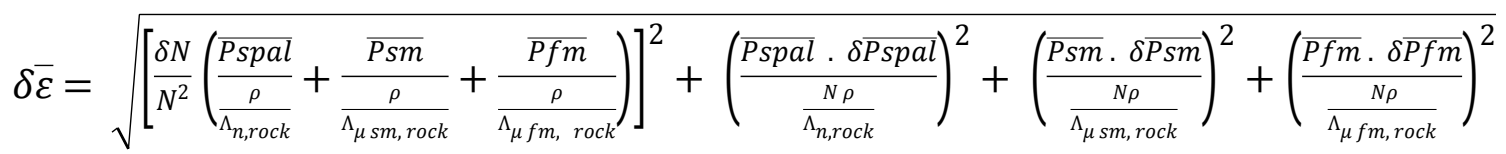

530 where $\mathrm{N}, \delta \mathrm{N}$ and $\delta \bar{\varepsilon}$ are the measured concentration of the studied nuclide, its $1 \sigma$ uncertainty, and 531 the error in the denudation rates, respectively. $\delta \mathrm{P} i$ represents the uncertainty in the cosmogenic 532 production rates for spallation and muons. Basinga attaches, to the spallogenic production 533 parameters, the uncertainties provided in Martin et al. (2017) as a function of the studied nuclide, 534 the scaling model and the ERA40 database (see table 7 of Martin et al. (2017). This represents, 535 on average, an uncertainty of less than $10 \%$, consistent with the value proposed in Balco et al. 536 (2008). This uncertainty accounts for variability resulting from both these production rate 537 calibrations and from the spatial scaling (Balco et al., 2008). We attached a value of $20 \%$ for 538 both muogenic production uncertainties based on the standard deviation of the surficial SLHL 539 estimate of Braucher et al. (2013). All these values can be easily changed and updated if needed 540 (see online supplementary information).

541 A more rigorous approach would consider all of the parameters in equation 4 and their 542 related uncertainties but would require a laborious partial derivation. This error propagation could 543 also be performed using a numerical approach based on a Monte Carlo simulation that explores 544 the range of all the input parameters (Puchol et al., 2017). Such an approach would require 545 further developments that are beyond the scope of the present tool.

\section{Conclusion}

$548 \quad$ Our sensitivity analysis suggests that inverting denudation rates from the cosmogenic 549 concentration measured at the basin outlet using the analytical approach, which assumes constant 550 attenuation lengths of muons in the rocks and spatially variable denudation rates, remains as 551 accurate as the second, more sophisticated, iterative approach. The attenuation lengths of muons 552 have little impact on the final denudation rates determined whatever the latitude, denudation and 
553 relief of the studied basin. The analytical approach is moreover computationally more rapid and 554 does not require the relatively unrealistic hypothesis that denudation rates are homogenous 555 throughout the studied basins.

556 Consequently, Basinga is based on these results and calculates the denudation rates using 557 the analytical approach (method 2). However, this method neglects past variations in the Earth's 558 magnetic field. To address this issue, through Basinga we developed a new simplified approach 559 for correcting for paleomagnetic changes. This approach is based on integration of the production 560 rates during the equivalent exposure time, which is approximated at the basin scale by dividing 561 the present-day basin-average production rates by the cosmogenic concentration measured at the 562 outlet.

563 Our analysis also shows that the choice of the scaling model may be critical in some 564 regions where the Lal/Stone and LSD factors can differ by up to $30 \%$ leading to large 565 discrepancies in the denudation results. Because calibration data are sparse in many regions of the 566 world, it is difficult to determine which of the two models is the most accurate. New calibration 567 data sites are therefore needed, especially in regions where the scaling factors determined by two 568 schemes differ strongly. Until such data are made available, in regions of low relief with a strong 569 difference between the two models, both models should be used in the calculation to provide a 570 range of possible denudation values. Consequently, the two models are available in Basinga. 571 However, calculation of scaling factors using the LSD model is computationally longer, which 572 precludes application of this model to a large dataset. To overcome this limitation, we developed 573 in Basinga an alternative approach in which the LSD factors are interpolated for the whole basin 574 from the Lal/Stone factors. This interpolation is based on a polynomial law that is fitted using a 575 limited number of cells in which both models have been used to calculate scaling factors.

576 Basinga is a freely available GIS toolbox that provides two independent tools for 577 computing basin average cosmogenic scaling factors, cosmogenic ${ }^{10} \mathrm{Be},{ }^{3} \mathrm{He}$ and ${ }^{21} \mathrm{Ne}$ production 578 rates, and associated denudation rates, from the cosmogenic concentrations. It presents several 579 significant improvements with respect to the literature:

580 (1) it is based on user-friendly interfaces, for which comprehensive instructions and help are 581 provided. Its use does not require any particular skills in programming. 
582 (2) it can be run on either ArcGIS or QGIS. It is therefore the first existing tool which couples a 583 code-based program to calculate the cosmogenic production and denudation rates with the 584 powerful skills of a GIS system.

(3) it computes the scaling factors and cosmogenic rates in a few minutes for several catchments together and allows quick processing of large datasets.

(4) it is the first existing tool which calculates the LSD scaling factors at the basin scale

(5) it is the first tool that provides, at the basin scale, a correction for paleomagnetic changes, ice cover and geology.

590 Basinga can be easily downloaded from the Online Supplementary Information and installed 591 following the instructions "Getting Started" document, also provided online. The 592 parameterization can be easily updated or changed if needed following the instructions given in 593 the "Getting Started" document.

\section{Acknowledgements}

596 We thank Jérôme Lavé and Maarten Lupker for fruitful discussions about cosmogenic nuclides 597 and denudation rates. We also thank Pauline Collon and Christine Fay-Varnier for their 598 assistance and help with programing in Python. We are also thankful to the associate editor and 599 two anonymous reviewers for their reading and comments which greatly improved the quality of 600 this manuscript. We dedicate this work to the fictional, but Nobel-Prize-worthy Sheldon Cooper, 601 from Caltech, who greatly inspired the name of our tool. This is CRPG contribution 2692.

\section{References}

605 Balco, G., 2017. Production rate calculations for cosmic-ray-muon-produced 10Be and 26Al 606 benchmarked against geological calibration data. Quat. Geochronol. 39, 150-173. doi:10.1016/j.quageo.2017.02.001

Balco, G., Briner, J., Finkel, R.C., Rayburn, J.A., Ridge, J.C., Schaefer, J.M., 2009. Regional beryllium-10 production rate calibration for late-glacial northeastern North America. Quat. Geochronol. 4, 93-107. doi:10.1016/j.quageo.2008.09.001

612 calculating surface exposure ages or erosion rates from 10Be and 26Al measurements. Quat. 
613

614

615

616

617

618

619

620

621

622

623

624

625

626

627

628

629

630

631

632

633

634

635

636

637

638

639

640

641

642

643

Geochronol. 3, 174-195. doi:10.1016/j.quageo.2007.12.001

Bierman, P., Steig, E.J., 1996. ESTIMATING RATES OF DENUDATION USING COSMOGENIC ISOTOPE ABUNDANCES IN SEDIMENT. Earth Surf. Process. Landforms 21, 125-139.

Borchers, B., Marrero, S., Balco, G., Caffee, M., 2015. Geological Calibration of Spallation Production Rates in the CRONUS-Earth Project.

Braucher, R., Bourlès, D., Merchel, S., Vidal Romani, J., Fernadez-Mosquera, D., Marti, K., Léanni, L., Chauvet, F., Arnold, M., Auma??tre, G., Keddadouche, K., 2013. Determination of muon attenuation lengths in depth profiles from in situ produced cosmogenic nuclides. Nucl. Instruments Methods Phys. Res. Sect. B Beam Interact. with Mater. Atoms 294, 484490. doi:10.1016/j.nimb.2012.05.023

Braucher, R., Merchel, S., Borgomano, J., Bourlès, D.L., 2011. Production of cosmogenic radionuclides at great depth : A multi element approach. Earth Planet. Sci. Lett. 309, 1-9. doi:10.1016/j.eps1.2011.06.036

Brown, E.T.., Stallard, R.F., Larsen, M.C., Raisbeck, G.M., Yiou, F., 1995. Denudation rates determined from the accumulation of in situ-produced 10Be in the Luquillo Experimental Forest, Puerto Rico. Earth Planet. Sci. Lett. 129, 193-202.

Carretier, S., Regard, V., Vassallo, R., Aguilar, G., Martinod, J., Riquelme, R., Christophoul, F., Charrier, R., Gayer, E., Farías, M., Audin, L., Lagane, C., 2015. Differences in 10Be concentrations between river sand, gravel and pebbles along the western side of the central Andes. Quat. Geochronol. 27, 33-51. doi:10.1016/j.quageo.2014.12.002

Charreau, J., Blard, P.H., Puchol, N., Avouac, J.P., Lallier-Vergès, E., Bourlès, D., Braucher, R., Gallaud, A., Finkel, R., Jolivet, M., Chen, Y., Roy, P., 2011. Paleo-erosion rates in Central Asia since 9Ma: A transient increase at the onset of Quaternary glaciations? Earth Planet. Sci. Lett. 304, 85-92. doi:10.1016/j.eps1.2011.01.018

Chmeleff, J., von Blanckenburg, F., Kossert, K., Jakob, D., 2010. Determination of the 10Be half-life by multicollector ICP-MS and liquid scintillation counting. Nucl. Instruments Methods Phys. Res. Sect. B Beam Interact. with Mater. Atoms 268, 192-199.

Danielson, J.J., Gesch, D.B., 2011. Global Multi-resolution Terrain Elevation Data 2010. U.S. Geol. Surv. Open-File Rep. 2011 1073, 26 p.

Delunel, R., van der Beek, P.A., Carcaillet, J., Bourlès, D.L., Valla, P.G., 2010. Frost-cracking 
644

645

646

647

648

649

650

651

652

653

654

655

656

657

658

659

660

661

662

663

664

665

666

667

668

669

670

671

672

673

674

control on catchment denudation rates: Insights from in situ produced 10Be concentrations in stream sediments (Ecrins-Pelvoux massif, French Western Alps). Earth Planet. Sci. Lett. 293, 72-83. doi:10.1016/j.eps1.2010.02.020

Derrieux, F., Siame, L.L., Bourlès, D.L., Chen, R., Braucher, R., Léanni, L., Lee, J., Chu, H., Byrne, T.B., 2014. How fast is the denudation of the Taiwan mountain belt? Perspectives from in situ cosmogenic 10 Be. J. Asian Earth Sci. 88, 230-245. doi:10.1016/j.jseaes.2014.03.012

Desilets, D., Zreda, M., Prabu, T., 2006. Extended scaling factors for in situ cosmogenic nuclides: New measurements at low latitude. Earth Planet. Sci. Lett. 246, 265-276.

Dibiase, R.A., 2018. Increasing vertical attenuation length of cosmogenic nuclide production on steep slopes negates topographic shielding corrections for catchment erosion rates. Earth Surf. Dyn. Discuss. 1-17.

Dunai, T.J., 2001. Influence of secular variation of the geomagnetic field on production rates of in situ produced cosmogenic nuclides. Earth Planet. Sci. Lett. 193, 197-212.

Dymond, J.R., Betts, H.D., Schierlitz, C.S., 2010. An erosion model for evaluating regional landuse scenarios. Environ. Model. Softw. 25, 289-298. doi:10.1016/j.envsoft.2009.09.011

Fox, M., Leith, K., Bodin, T., Balco, G., Shuster, D.L., 2015. Rate of fluvial incision in the Central Alps constrained through joint inversion of detrital $10 \mathrm{Be}$ and thermochronometric data. Earth Planet. Sci. Lett. 411, 27-36. doi:10.1016/j.eps1.2014.11.038

Godard, V., Bourles, D.L., Spinabella, F., Burbank, D.W., Bookhagen, B., Fisher, G.B., Moulin, A., Leanni, L., 2014. Dominance of tectonics over climate in Himalayan denudation. Geology 42, 243-246. doi:10.1130/G35342.1

Godard, V., Burbank, D.W., Bourlès, D.L., Bookhagen, B., Braucher, R., Fisher, G.B., 2012. Impact of glacial erosion on ${ }^{10} \mathrm{Be}$ concentrations in fluvial sediments of the Marsyandi catchment, central Nepal. J. Geophys. Res. 117, F03013. doi:10.1029/2011JF002230

Gosse, J.C., Phillips, F.M., 2001. Terrestrial in situ cosmogenic nuclides: theory and application. Quat. Sci. Rev. 20, 1475-1560.

Guillon, H., Mugnier, J., Buoncristiani, J., Carcaillet, J., Godon, C., Beek, P. Van Der, Vassallo, R., 2015. Improved discrimination of subglacial and periglacial erosion using $10 \mathrm{Be}$ concentration measurements in subglacial and supraglacial sediment load of the Bossons glacier ( Mont Blanc massif , France ) 1215, 1202-1215. doi:10.1002/esp.3713 
675 Heisinger, B., Lal, D., Jull, A.J.T., Kubik, P., Ivy-Ochs, S., Knie, K., Nolte, E., 2002a. Production 676 of selected cosmogenic radionuclides by muons; 2. Capture of negative muons. Earth Planet. 677

Heisinger, B., Lal, D., Jull, A.J.T., Kubik, P., Ivy-Ochs, S., Neumaier, S., Knie, K., Lazarev, V., Nolte, E., 2002b. Production of selected cosmogenic radionuclides by muons; 1. Fast muons. Earth Planet. Sci. Lett. 200, 345-355.

Herman, F., Rhodes, E.J., Braun, J., Heiniger, L., 2010. Uniform erosion rates and relief amplitude during glacial cycles in the Southern Alps of New Zealand, as revealed from OSL-thermochronology. Earth Planet. Sci. Lett. doi:10.1016/j.eps1.2010.06.019

Hippe, K., Kober, F., Zeilinger, G., Ivy-Ochs, S., Maden, C., Wacker, L., Kubik, P.W., Wieler, R., 2012. Quantifying denudation rates and sediment storage on the eastern Altiplano, Bolivia, using cosmogenic 10Be, 26Al, and in situ 14C. Geomorphology 179, 58-70. doi:10.1016/j.geomorph.2012.07.031

Kaplan, M.R., Strelin, J.A., Schaefer, J.M., Denton, G.H., Finkel, R.C., Schwartz, R., Putnam, A.E., Vandergoes, M.J., Goehring, B.M., Travis, S.G., 2011. In-situ cosmogenic 10 Be production rate at Lago Argentino, Patagonia : Implications for late-glacial climate chronology. Earth Planet. Sci. Lett. doi:10.1016/j.eps1.2011.06.018

Kelly, M.A., Lowell, T.V., Applegate, P.J., Phillips, F.M., Schaefer, J.M., Smith, C.A., Kim, H., Leonard, K.C., Hudson, A.M., 2015. A locally calibrated, late glacial 10Be production rate from a low-latitude, high-altitude site in the Peruvian Andes. Quat. Geochronol. 26, 70-85.

Kober, F., Al, V., Ivy-ochs, S., Kubik, P.W., Wieler, R., 2011. The cosmogenic Ne - 10 Be data Ne production rate in quartz evaluated on a large set of existing 302, 163-171. doi:10.1016/j.epsl.2010.12.008

Lal, D., 1991. Cosmic ray labeling of erosion surfaces: in situ nuclide production rates and erosion models. Earth Planet. Sci. Lett. 104, 424-439.

Lifton, N., 2015. Implications of two Holocene time-dependent geomagnetic models for cosmogenic nuclide production rate scaling. Earth Planet. Sci. Lett. 433, 257-268. doi:10.1016/j.eps1.2015.11.006

Lifton, N., Sato, T., Dunai, T.J., 2014. Scaling in situ cosmogenic nuclide production rates using analytical approximations to atmospheric cosmic-ray fluxes. Earth Planet. Sci. Lett. 386, 149-160. doi:10.1016/j.epsl.2013.10.052 
706 Lifton, N.A., Bieber, J.W., Clem, J.M., Duldig, M.L., Evenson, P., Humble, J.E., Pyle, R., 2005. 707 Addressing solar modulation and long-term uncertainties in scaling secondary cosmic rays 708

Lupker, M., Blard, P.H., Lavé, J., France-Lanord, C., Leanni, L., Puchol, N., Charreau, J., Bourlès, D., 2012. 10Be-derived Himalayan denudation rates and sediment budgets in the Ganga basin. Earth Planet. Sci. Lett. 333-334, 146-156. doi:10.1016/j.eps1.2012.04.020

Marrero, S.M., Phillips, F.M., Borchers, B., Lifton, N., Aumer, R., Balco, G., 2015. Cosmogenic Nuclide Systematics and the CRONUScalc Program. Quat. Geochronol. 31, 160-187. doi:10.1016/j.quageo.2015.09.005

Martin, L.C.P., Blard, P.H., Balco, G., Lavé, J., Delunel, R., Lifton, N., Laurent, V., 2017. The CREp program and the ICE-D production rate calibration database : A fully parameterizable and updated online tool to compute cosmic- ray exposure ages. Quat. Geochronol. 38, 2549. doi:10.1016/j.quageo.2016.11.006

Martin, L.C.P., Blard, P.-H., Lavé, J., Braucher, R., Lupker, M., Condom, T., Charreau, J., Mariotti, V., Davy, E., 2015. In situ cosmogenic 10Be production rate in the High Tropical Andes. Quat. Geochronol. 30, 54-68. doi:10.1016/j.quageo.2015.06.012

Molliex, S., Rabineau, M., Leroux, E., Bourlès, D.L., Authemayou, C., Aslanian, D., Chauvet, F., Civet, F., Jouët, G., 2016. Multi-approach quantification of denudation rates in the Gulf of Lion source-to-sink system ( SE France ). Earth Planet. Sci. Lett. 444, 101-115. doi:10.1016/j.eps1.2016.03.043

Mudd, M.S., Harel, M.A., Hurst, M.D., Grieve, S.W.D., Marrero, S.M., 2016. The CAIRN method: Automated, reproducible calculation of catchment-averaged denudation rates from cosmogenic nuclide concentrations. Earth Surf. Dyn. 4, 655-674. doi:10.5194/esurf-4-6552016

Muscheler, R., Beer, J., Kubik, P.W., Synal, H. a., 2005. Geomagnetic field intensity during the last 60,000 years based on 10Be and 36Cl from the Summit ice cores and 14C. Quat. Sci. Rev. 24, 1849-1860. doi:10.1016/j.quascirev.2005.01.012

Nishiizumi, K., Kohl, C.P., Winterer, E.L., Klein, J., Middleton, R., 1989. Cosmic ray production rates of Be-10 and Al-26 in quartz from glacially polished rocks. J. Geophys. Res. 94, 907917. doi:10.1029/JB094iB12p17907

Phillips, F.M., Argento, D.C., Balco, G., Caffee, M.W., Clem, J., Dunai, T.J., Finkel, R., 
Goehring, B., Gosse, J.C., Hudson, A.M., Jull, A.J.T., Kelly, M.A., Kurz, M., Lal, D., Lifton, N., Marrero, S.M., Nishiizumi, K., Reedy, R.C., Schaefer, J., Stone, J.O.H., Swanson, T., Zreda, M.G., 2016. Quaternary Geochronology The CRONUS-Earth Project : A synthesis. Quat. Geochronol. 31, 119-154. doi:10.1016/j.quageo.2015.09.006

Pigati, J.S., Lifton, N.A., 2004. Geomagnetic effects on time-integrated cosmogenic nuclide production with emphasis on in situ 14C and 10Be. Earth Planet. Sci. Lett. 226, 193-205.

Portenga, E.W., Bierman, P.R., 2011. Understanding Earth's eroding surface with 10Be. GSA Today 21, 4-10. doi:10.1130/G111A.1

Puchol, N., Charreau, J., Blard, P., Lavé, J., Dominguez, S., Pik, R., Saint-carlier, D., ASTER Team, 2017. Limited impact of Quaternary glaciations on denudation rates in central Asia. Geol. Soc. Am. Bull. 129, 479-499.

Riccio, S.J., Fitzgerald, P.G., Benowitz, J.A., Roeske, S.M., 2014. The role of thrust faulting in the formation of the eastern Alaska Range : Thermochronological constraints from the ... Geochemistry Geophys. Geosystems 1-23. doi:10.1002/2014TC003646

Sato, T., Yasuda, H., Niita, K., Sihver, L., 2008. Development of PARMA : PHITS-based Analytical Radiation Model in the Atmosphere Development of PARMA : PHITS-based Analytical Radiation Model in the Atmosphere 170, 244-259.

Schaller, M., Ehlers, T.A., 2006. Limits to quantifying climate driven changes in denudation rates with cosmogenic radionuclides 248, 153-167. doi:10.1016/j.epsl.2006.05.027

Scherler, D., Bookhagen, B., Strecker, M.R., 2014. Tectonic control on ${ }^{10}$ Be-derived erosion rates in the Garhwal Himalaya, India. J. Geophys. Res. Earth Surf. 119, 83-105. doi:10.1002/2013JF002955

Schildgen, T.F., Phillips, W.M., Purves, R.S., 2005. Simulation of snow shielding corrections for cosmogenic nuclide surface exposure studies. Geomorphology 64, 67-85. doi:10.1016/j.geomorph.2004.05.003

Siame, L., Angelier, J., Chen, R., Godard, V., Derrieux, F., Bourlès, D.L., Braucher, R., 2011. Erosion rates in an active orogen ( NE-Taiwan ): A confrontation of cosmogenic measurements with river suspended loads. Quat. Geochronol. 6, 246-260. doi:10.1016/j.quageo.2010.11.003

Stone, J.O., 2000. Air pressure and cosmogenic isotope production. J. Geophyisical Res. 105, 753-759. 
768

769

770

771

772

773

774

775

776

777

778

779

780

781

782

783

784

785

786

787

788

789

790

791

792

793

794

795

796

797

798

Stroeven, A.P., Heyman, J., Fabel, D., Björck, S., Caffee, M.W., Fredin, O., Harbor, J.M., 2015. A new Scandinavian reference 10Be production rate. Quat. Geochronol. 29, 104-115. doi:10.1016/j.quageo.2015.06.011

Uppala, S.M., KÅllberg, P.W., Simmons, A.J., Andrae, U., Bechtold, V.D.C., Fiorino, M., Gibson, J.K., Haseler, J., Hernandez, A., Kelly, G.A., Li, X., Onogi, K., Saarinen, S., Sokka, N., Allan, R.P., Andersson, E., Arpe, K., Balmaseda, M.A., Beljaars, A.C.M., Berg, L. Van De, Bidlot, J., Bormann, N., Caires, S., Chevallier, F., Dethof, A., Dragosavac, M., Fisher, M., Fuentes, M., Hagemann, S., Hólm, E., Hoskins, B.J., Isaksen, L., Janssen, P.A.E.M., Jenne, R., Mcnally, A.P., Mahfouf, J.-F., Morcrette, J.-J., Rayner, N.A., Saunders, R.W., Simon, P., Sterl, A., Trenberth, K.E., Untch, A., Vasiljevic, D., Viterbo, P., Woollen, J., 2005. The ERA-40 re-analysis. Q. J. R. Meteorol. Soc. 131, 2961-3012. doi:10.1256/qj.04.176

Valet, J., Meynadier, L., Guyodo, Y., 2005. Geomagnetic dipole strength and reversal rate over the past two million years 435, 5-8. doi:10.1038/nature03674

Whipp, D.M., Ehlers, T.A., Blythe, A.E., Huntington, K.W., Hodges, K. V, Burbank, D.W., 2007. Plio-Quaternary exhumation history of the central Nepalese Himalaya : 2 .

Thermokinematic and thermochronometer age prediction model 26, 1-23. doi:10.1029/2006TC001991

Wittmann, H., Blanckenburg, F. Von, Kruesmann, T., Norton, K.P., Kubik, P.W., 2007. Relation between rock uplift and denudation from cosmogenic nuclides in river sediment in the Central Alps of Switzerland 112, 1-20. doi:10.1029/2006JF000729

Wittmann, H., Blanckenburg, F. Von, Maurice, L., Guyot, J., Filizola, N., Kubik, P.W., 2011. Sediment production and delivery in the Amazon River basin quantified by in situ produced cosmogenic nuclides and recent river loads. doi:10.1130/B30317.1

Wittmann, H., von Blanckenburg, F., 2009. Cosmogenic nuclide budgeting of floodplain sediment transfer. Geomorphology 109, 246-256. doi:10.1016/j.geomorph.2009.03.006

\section{Figure captions and tables:}

Fig. 1:. Worldwide comparison of the LSD and Lal/Stone models. The map at the top shows the difference (in \%) between scaling factors calculated using the Lal/Stone and the LSD models, based on data from the ERA40 and the GMTED2010 databases (Danielson and Gesch, 2011; 
799 Uppala et al., 2005). The white circles indicate the locations of several vertical profiles where we 800 also calculated the difference between the two models, as shown in the figures below the map. 801 The red circles show the locations of the calibration data sites according to the ICE-D database 802 (Martin et al., 2017). The yellow stars show the location of the drainage basins that are studied 803 for the sensitivity analyze.

804

Fig. 2: a. Maximum elevation against latitude calculated using a $1^{\circ}$ interval. The red circles indicate the positions of the calibration data sites; b. possible ranges for the difference between the LSD and Lal/Stone scaling model against latitude using a $10^{\circ}$ interval.

Fig. 3: Variation in the attenuation length of muons in rock for ${ }^{10} \mathrm{Be}$ against the denudation rates and atmospheric pressures if a single exponential is assumed (modified after Balco, 2017).

Fig. 4: Flow chart showing the process used to compute and invert the theoretical basin average cosmogenic concentration of the studied basins in order to test the sensitivity of the methods and scaling model.

Fig. 5: Differences between the theoretical and inverted denudation rates as a function of the theoretical denudation for the two methods. The theoretical concentrations were calculated either without (top) or with (bottom) time integration.

820 Fig. 6: Results of inversion using the analytical approach (method 3) and the Lal/Stone model 821 for (a) the Marshyangdi basin and (b) the Susitna basin (see figure 1 for location). The frequency 822 diagrams show the distribution of elevation and denudation rates throughout the basin. The 823 vertical bars indicate the theoretical mean (red) and the results of the inversion if the time is 824 integrated or not. The other diagrams show the Stone factors against the LSD factor and the 825 difference between the two as a function of elevation for 10000 cells throughout the basin. The 826 red and blue dots were calculated without and with time integration, respectively. 
828 Fig. 7: Results of inversion with time integration using the analytical approach (method 3) and the Lal/Stone model for the Maroni basin (see figure 1 for location). See figure 5 for more 830 information.

Fig. 8: Computing time using Basinga. (a) Computing time needed to calculate the LSD scaling factors with time integration as a function of the number of cells and the surface area of the basin (cell size $=90 \mathrm{~m}$ ). (b) Computing time needed to calculate the Lal/Stone factors and the LSD using a polynomial fit without time integration. All calculations were performed on a laptop with a $2.6 \mathrm{GHz}$ processor.

Fig. 9: Mean and maximum difference between the theoretical, true LSD scaling factors and the LSD factors calculated from the Lal/stone factors and a polynomial law fitted using a limited number of cells. The differences are plotted against the number of cells used for the fit and are 841 shown for different polynomial degrees.

Fig. 10: Differences in \% between the "true" basin average denudation and the inverted denudation rate when the attenuation length of muons in the rocks is assumed to be constant with a value of $4814 \mathrm{~g} / \mathrm{cm}^{2}$ (Braucher et al., 2013). The difference is plotted as a function of the relief of the basin and the distribution of the denudation within the basin. For computational efficiency and simplicity, the true rates were calculated using the Lal/Stone factors. The results were determined for $5^{\circ}$ latitude but are very similar for the other latitudes. The differences are always negative because the constant value of the attenuation length that is used for the inversion is higher than the pre-calculated values of Balco (2017) (Fig. 3).

852 Fig. 11: Contour diagrams showing the biases (in \%) of the scaling factors if the time is not 853 integrated to account for past changes in the Earth's magnetic field. The biases were calculated 854 using the LSD model and the Muscheler ${ }^{10} \mathrm{Be}$ atmospheric geomagnetic database (Muscheler et 855 al., 2005) for different denudation rates (i.e. characteristic integration time), at different 856 elevations and latitudes. The ranges of elevation respect the maximum possible altitude 
857 observed at each latitude in the GMTED2010 database (Danielson and Gesch, 2011). The 858 integration times were calculated based on the attenuation length of neutrons in the rocks.

860 Table 1 -possible methods used to calculate denudation rates from the cosmogenic concentration 861 measured in river sediments.

\section{Table 2: Results of the sensitivity analysis}

864 Inverted denudation rates for the studied basins, calculated using either the Lal/Stone or the LSD 865 scaling model and based on either method 1 or 2 . The theoretical cosmogenic concentrations 866 were calculated throughout the basin either with or without time integration as a function of the 867 local denudation, which is a simple linear function of the slope. $\varepsilon_{\text {lit }}, \varepsilon_{\min } / \varepsilon_{\max }$ and $\varepsilon_{\text {mean theo. indicate }}$ 868 the denudation rates reported in the literature, the minimum and maximum denudation rates 869 specified for the calculation, and the theoretical basin average denudation rates obtained based on 870 this range of values, respectively. 
Table 1 -possible methods used to calculate denudation rates from the cosmogenic concentration in river sediments

\begin{tabular}{|c|c|c|c|c|c|c|}
\hline $\begin{array}{l}\text { Method } \\
\text { number }\end{array}$ & $\begin{array}{l}\text { Muon } \\
\text { production }\end{array}$ & $\begin{array}{l}\text { Attenuation } \\
\text { lengths }\end{array}$ & Time & $\begin{array}{l}\text { Watershed } \\
\text { topography }\end{array}$ & $\begin{array}{l}\text { Resolution } \\
\text { method }\end{array}$ & Relevant references \\
\hline 1 & No & - & No & Single point & Analytical & Brown et al. (1995) \\
\hline 2 & $\begin{array}{c}\text { Two } \\
\text { exponentials }\end{array}$ & Constant & No & Pixel array & Analytical & $\begin{array}{l}\text { This study, Lupker et al. (2012), } \\
\text { Fox et al. (2015) }\end{array}$ \\
\hline 3 & $\begin{array}{l}\text { Single } \\
\text { exponential }\end{array}$ & Constant & No & Pixel array & Analytical & This study \\
\hline 4 & $\begin{array}{l}\text { Heisinger's } \\
\text { equations }\end{array}$ & Constant & Yes & Single point & Iterative & $\begin{array}{l}\text { Portenga et al. (2011); Balco et al. } \\
\qquad(2008)\end{array}$ \\
\hline 5 & $\begin{array}{c}\text { Two } \\
\text { exponentials }\end{array}$ & Constant & No & Pixel array & Iterative & Mudd et al., (2017) \\
\hline 6 & $\begin{array}{l}\text { Single } \\
\text { exponential }\end{array}$ & $\begin{array}{l}\text { Effective and } \\
\text { interpolated }\end{array}$ & Yes & Pixel array & Iterative & This study \\
\hline
\end{tabular}




\section{Table 2: Results of the sensitivity analysis}

Inverted denudation rates for the studied basins, calculated using either the Lal/Stone or the LSD scaling model and based on either method 1 or 2 . The theoretical cosmogenic concentrations were calculated throughout the basin either with or without time integration as a function of the local denudation, which is a simple

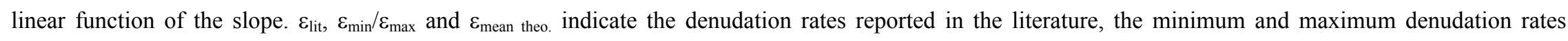
specified for the calculation, and the theoretical basin average denudation rates obtained based on this range of values, respectively.

\begin{tabular}{|c|c|c|c|c|c|c|c|c|c|c|c|}
\hline \multirow{3}{*}{$\begin{array}{c}\text { Name of } \\
\text { basin }\end{array}$} & \multirow{3}{*}{ Region } & \multirow{3}{*}{ Elevation $(\mathrm{m})$} & \multirow{3}{*}{$\varepsilon_{\mathrm{lit}}(\mathrm{m} / \mathrm{Ma})$} & \multirow{3}{*}{$\begin{array}{c}\varepsilon_{\min } / \varepsilon_{\max } \\
(\mathrm{m} / \mathrm{Ma})\end{array}$} & \multirow{3}{*}{$\begin{array}{c}\varepsilon_{\text {mean theo. }} \\
(\mathrm{m} / \mathrm{Ma})\end{array}$} & \multicolumn{4}{|c|}{$\varepsilon_{\text {inverted }}(\mathrm{m} / \mathrm{Ma})^{\mathrm{a}}$} & \multicolumn{2}{|c|}{$\varepsilon_{\text {inverted }}(\mathrm{m} / \mathrm{Ma})^{\mathrm{b}}$} \\
\hline & & & & & & \multicolumn{2}{|c|}{ Method 1} & \multicolumn{2}{|c|}{ Method 2 (no time) } & \multirow{2}{*}{$\begin{array}{l}\text { Method } 1 \\
\operatorname{LSD}(t=0)\end{array}$} & \multirow{2}{*}{$\frac{\text { Method 2(time }}{\text { LSD }}$} \\
\hline & & & & & & Lal/St & $\operatorname{LSD}(t=0)$ & Lal/St & $\operatorname{LSD}(t=0)$ & & \\
\hline Marsyangdi & Himalaya & $240-7920$ & $100-5000^{1}$ & $0-8000$ & 3058 & 3063 & 3060 & 3337 & 3330 & 3110 & 3337 \\
\hline Susitna & Alaska & $30-5350$ & $60-1000^{2}$ & $0-3000$ & 423 & 426 & 426 & 526 & 520 & 380 & 539 \\
\hline Maroni & $\begin{array}{l}\text { French } \\
\text { Guyana }\end{array}$ & $0-900$ & $10^{3}$ & $0-100$ & 11 & 12 & 11 & 12 & n.a & 11 & n.a \\
\hline Kuitun & Tianshan & $750-4820$ & $400^{4}$ & $0-1200$ & 453 & 454 & 454 & 462 & 463 & 461 & 478 \\
\hline Rhône & French Alps & $20-4440$ & $118^{5}$ & $0-800$ & 123 & 124 & 124 & 191 & 195 & 124 & 183 \\
\hline Lahuachaca & Altiplano & $3800-4500$ & $3-29^{6}$ & $0-600$ & 14 & 14 & 14 & 15 & 15 & 13 & 10 \\
\hline Tin & Andies & $470-4990$ & $160^{7}$ & $0-500$ & 164 & 165 & 165 & 173 & 168 & 195 & 164 \\
\hline Chambal & India & $120-1240$ & $7^{8}$ & $0-170$ & 8 & 9 & 9 & 8 & n.a & 8 & n.a \\
\hline Lanyang & Taïwan & $90-3520$ & $2000^{9}$ & $0-4800$ & 2093 & 2095 & 2095 & 2207 & 2230 & 2153 & 2230 \\
\hline Franz Josef & $\begin{array}{l}\text { New } \\
\text { Zealand } \\
\text { Alps }\end{array}$ & $10-3090$ & $\begin{array}{l}1800- \\
7000^{10}\end{array}$ & $0-8000$ & 2977 & 2982 & 2982 & 3419 & 3430 & 2934 & 3430 \\
\hline
\end{tabular}

${ }^{a}$ Theoretical concentration calculated without time integration and using either the Lal/Stone or the LSD model

b Theoretical concentration calculated with time integration using the LSD model only

${ }^{1}$ (Godard et al., 2012; Whipp et al., 2007); ${ }^{2}$ (Riccio et al., 2014); ${ }^{3}$ (Wittmann et al., 2011); ${ }^{4}$ (Puchol et al., 2017); ${ }^{5}$ (Molliex et al., 2016); ${ }^{6}\left(\right.$ Hippe et al., 2012); ${ }^{7}\left(\right.$ Carretier et al., 2015); ${ }^{8}$ (Lupker et al., 2012); ${ }^{9}$ (Siame et al., 2011); ${ }^{10}$ (Dymond et al., 2010)

n.a : Because of the size of the basins and their low denudation rates, the calculation using iterative method 2 based on LSD took too long to compute and was not possible 

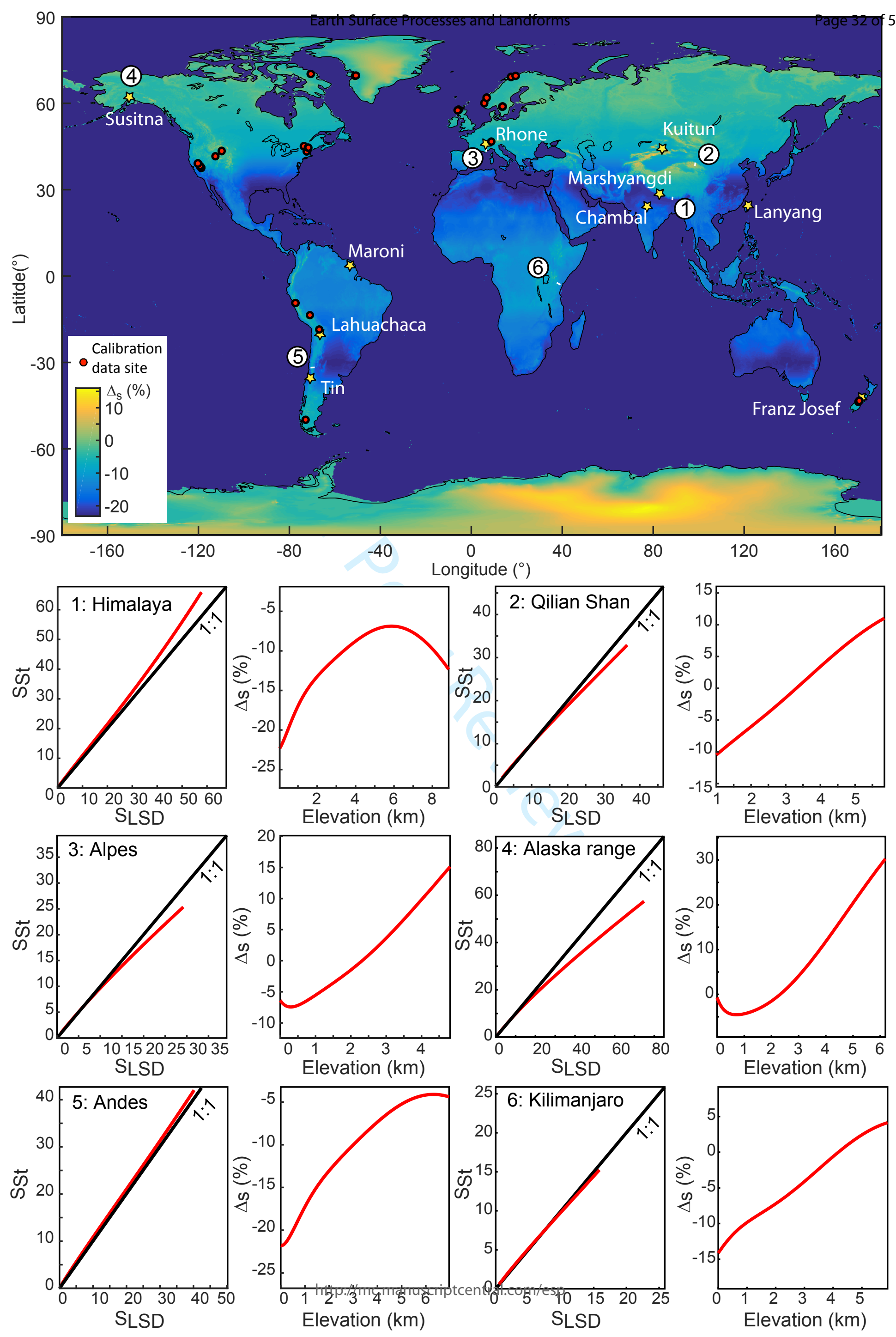


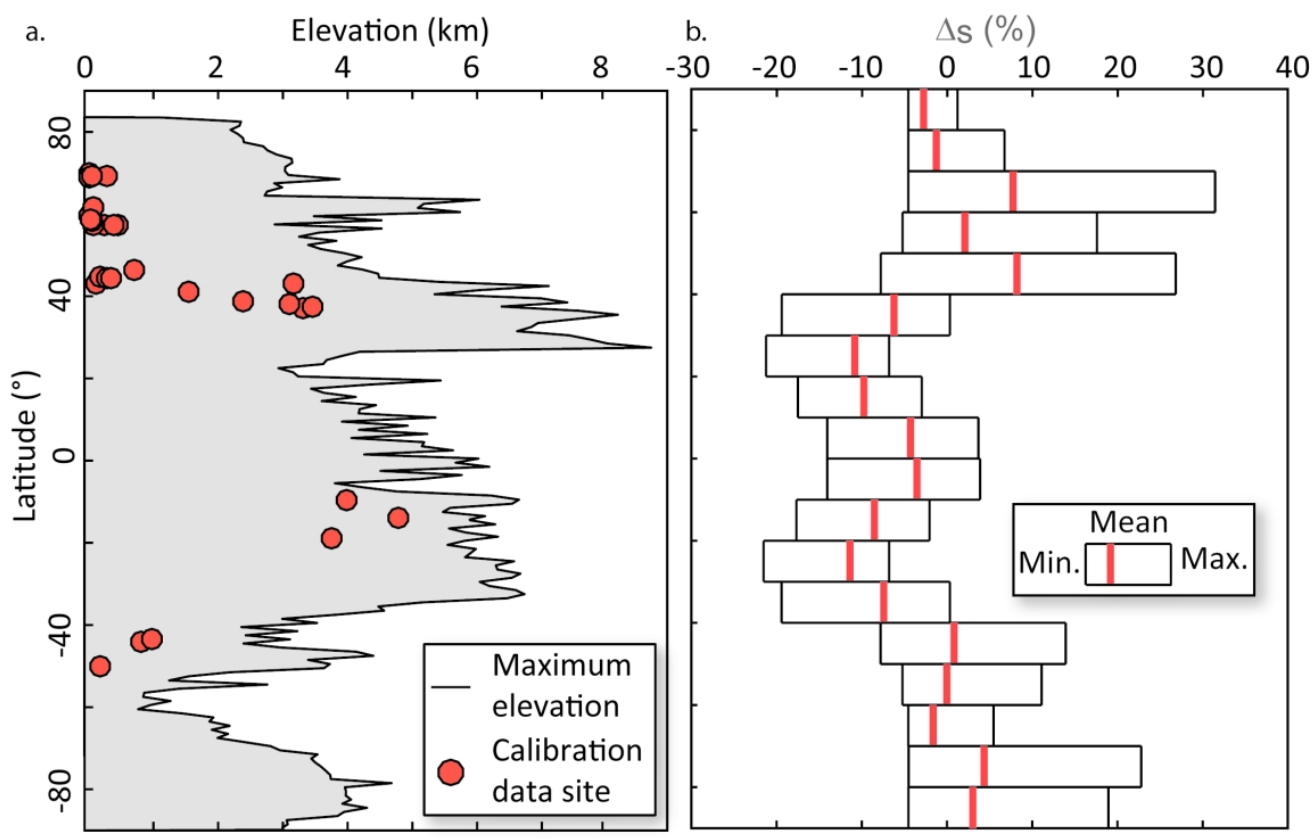

Fig. 2

$188 \times 155 \mathrm{~mm}(300 \times 300 \mathrm{DPI})$ 


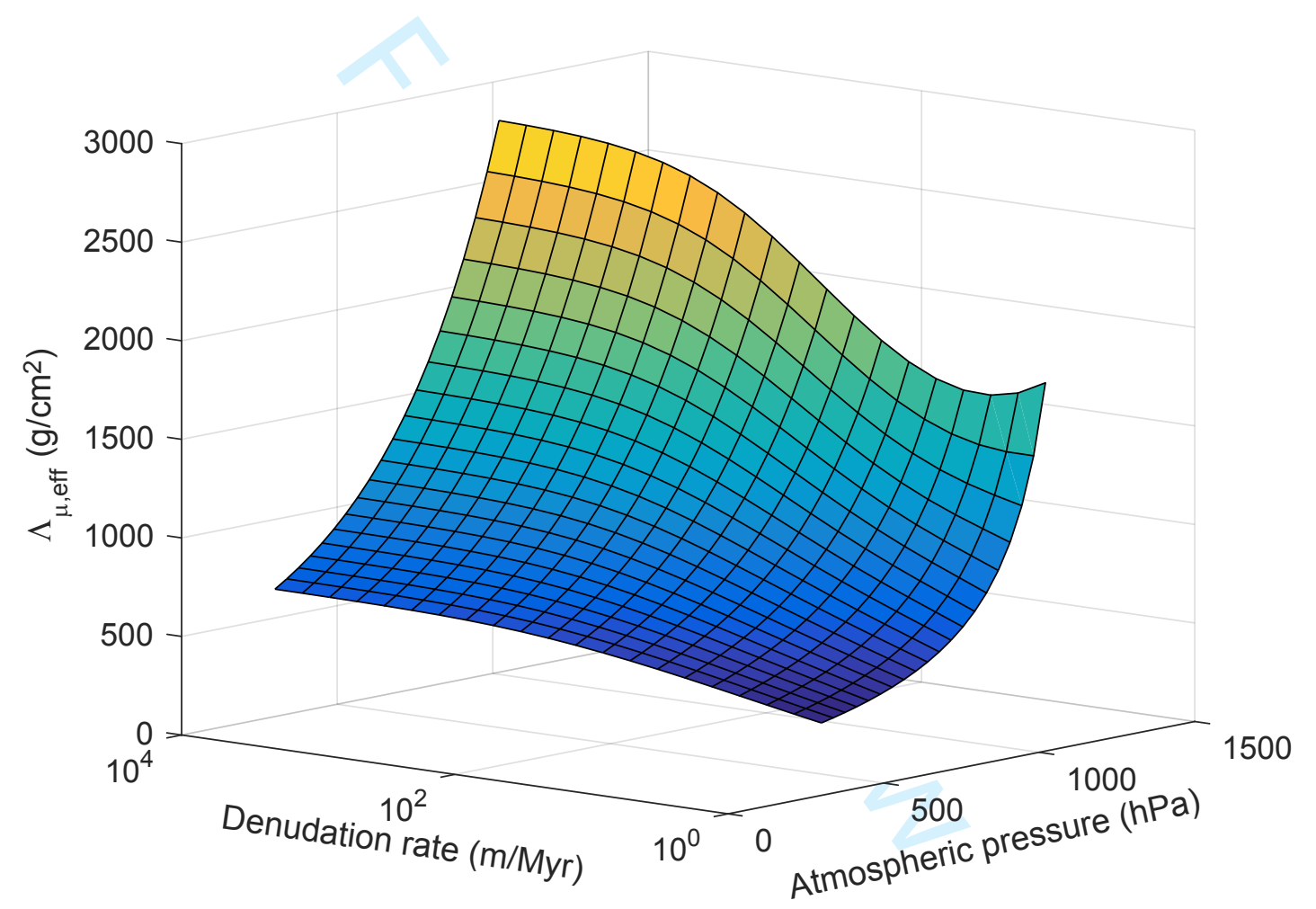

Fig. 3 


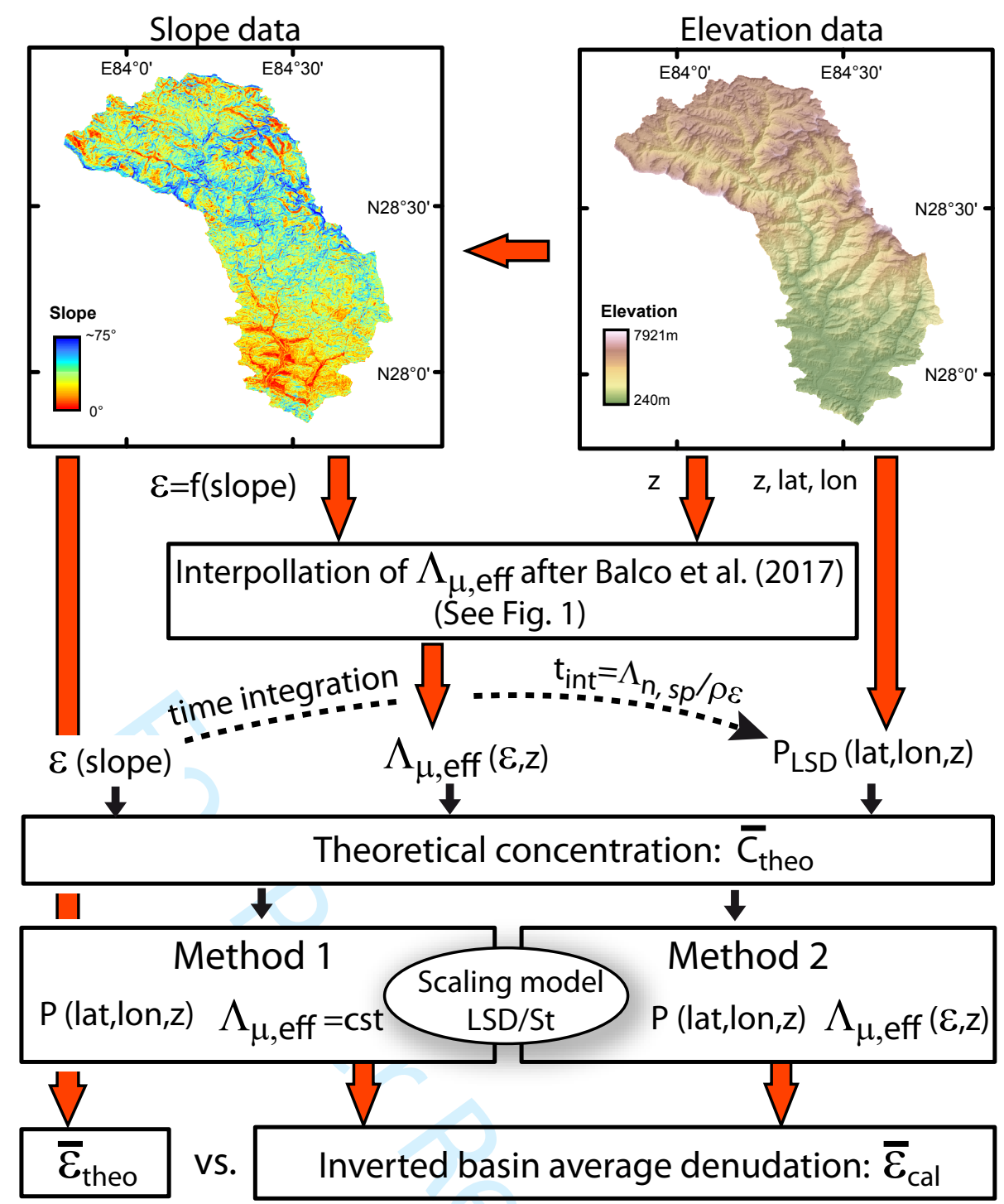

Fig. 4 
a.

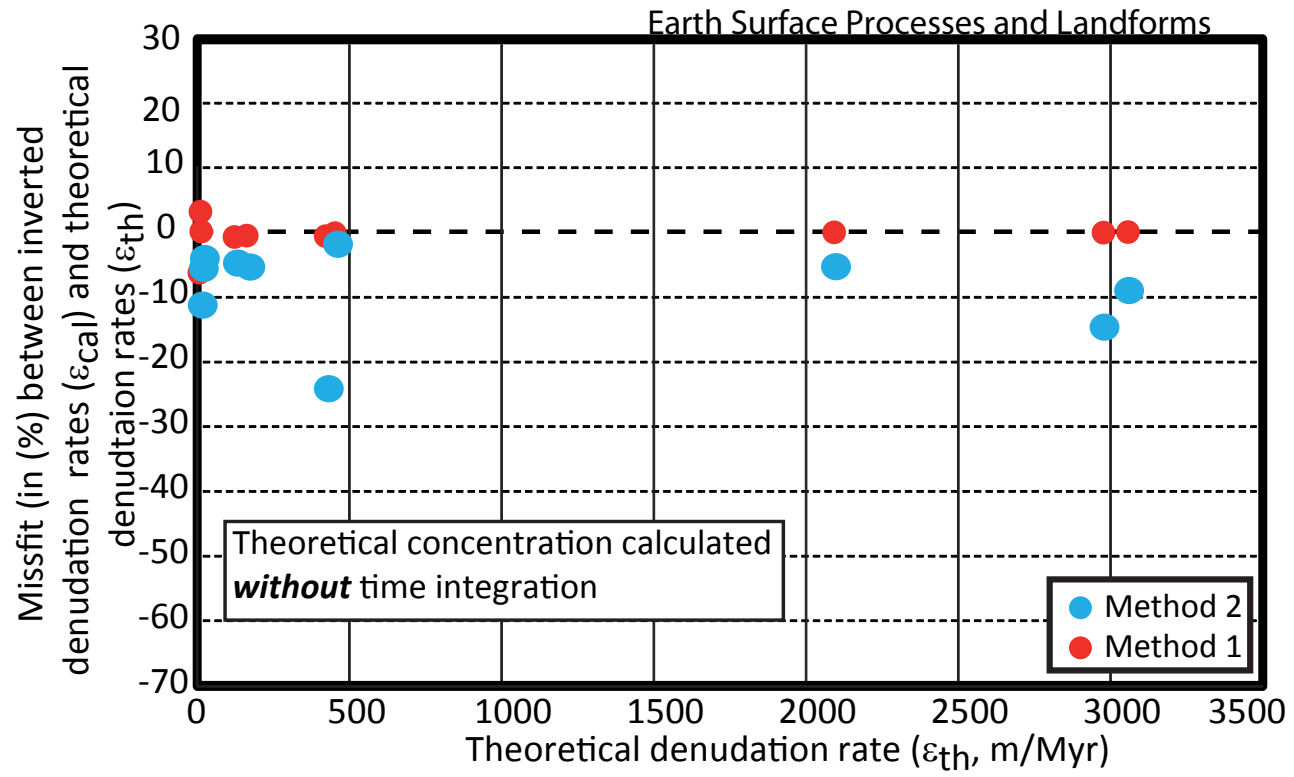

16 1 to. 18

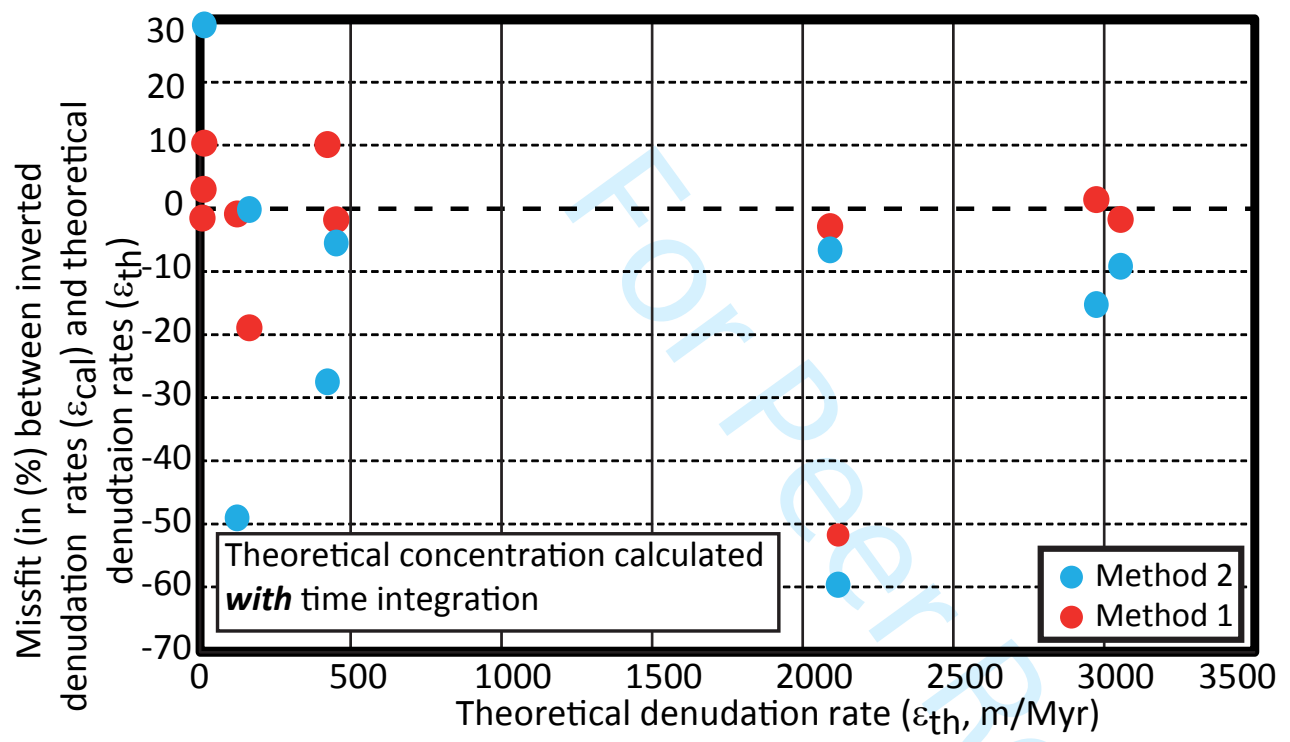

Fig. 5 

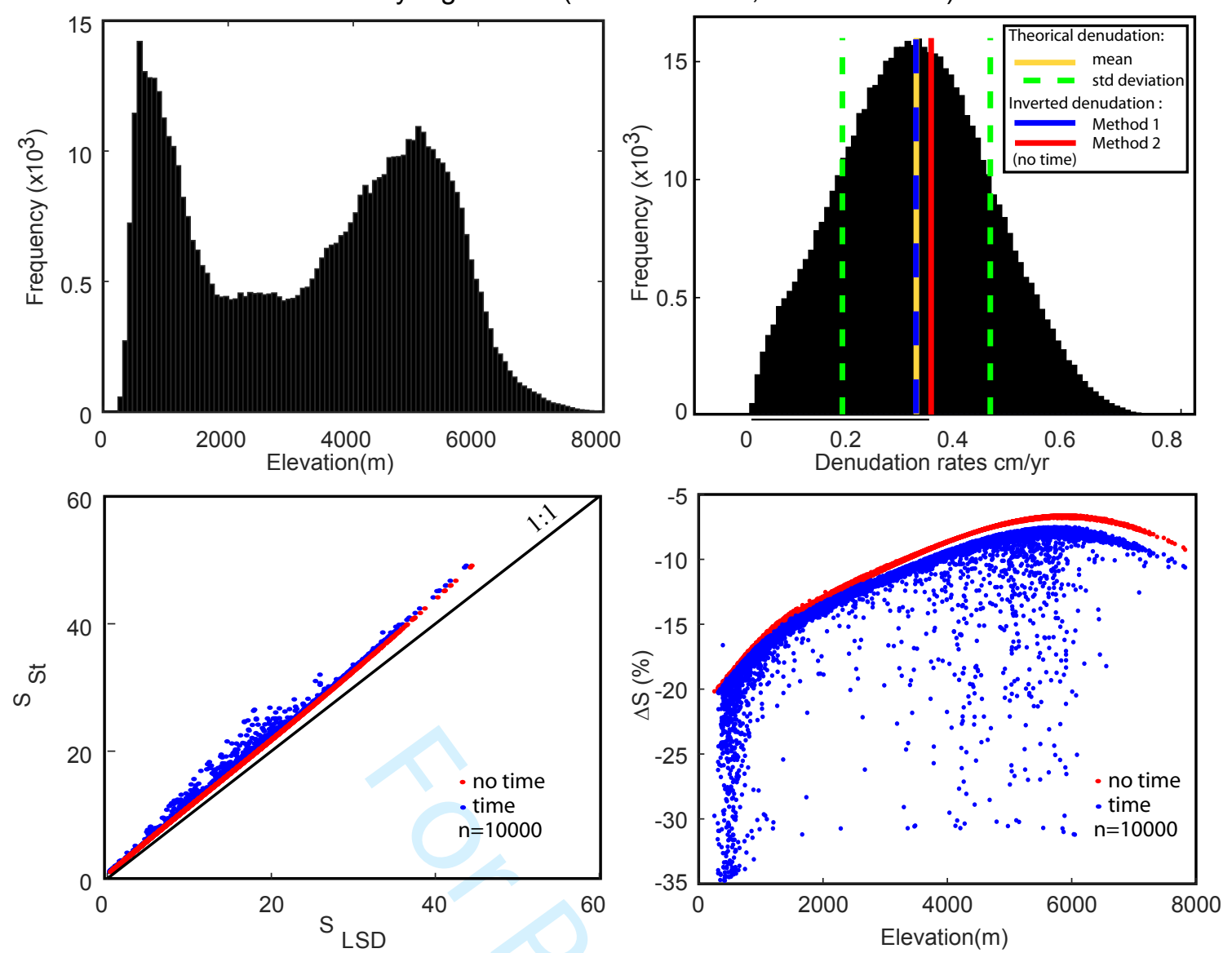

b.

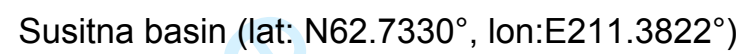
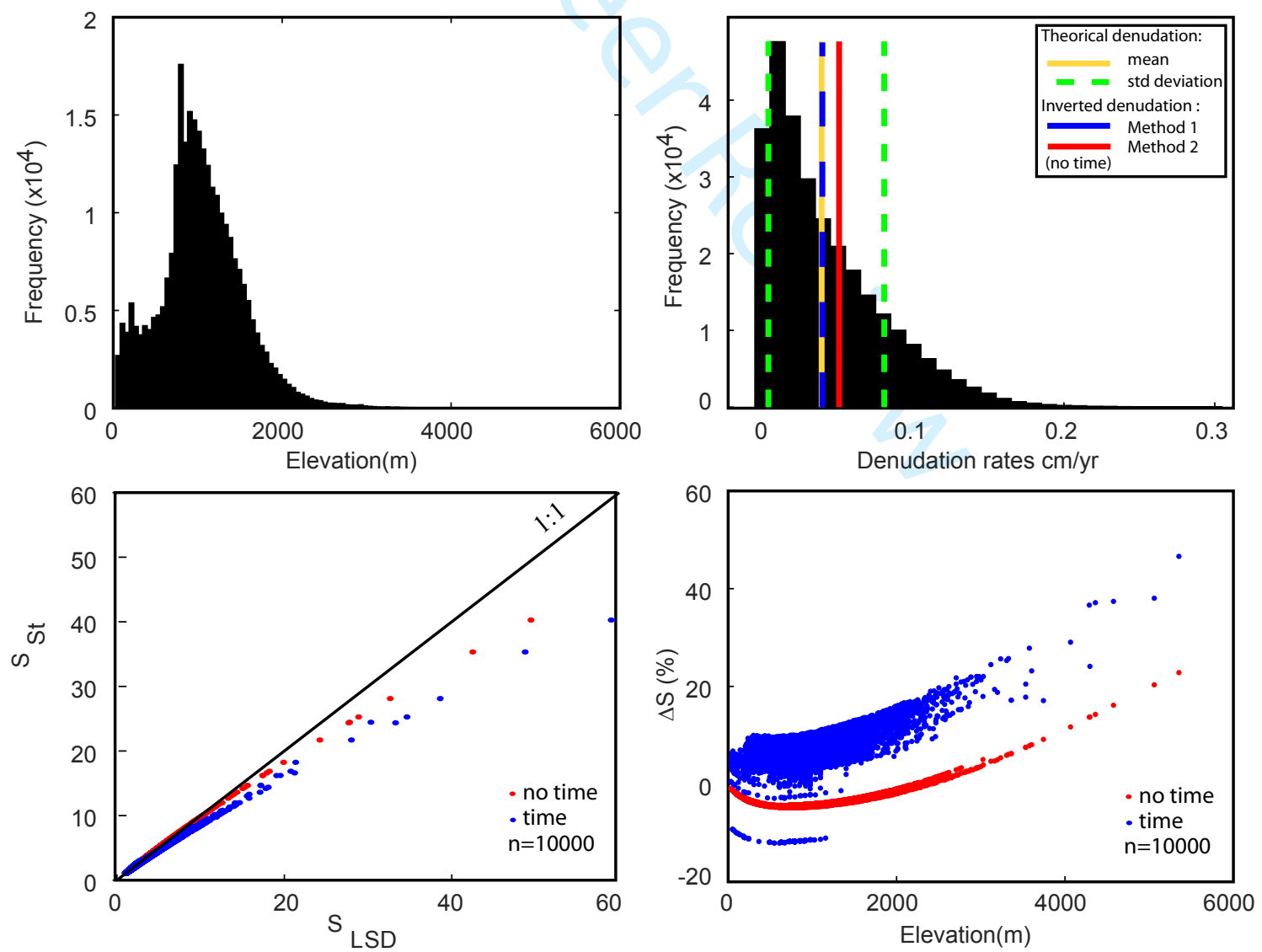

\section{Fig. 6}


Maroni basin (lat: N3.4683 ${ }^{\circ}$, Ion:E305.2154 ${ }^{\circ}$ )
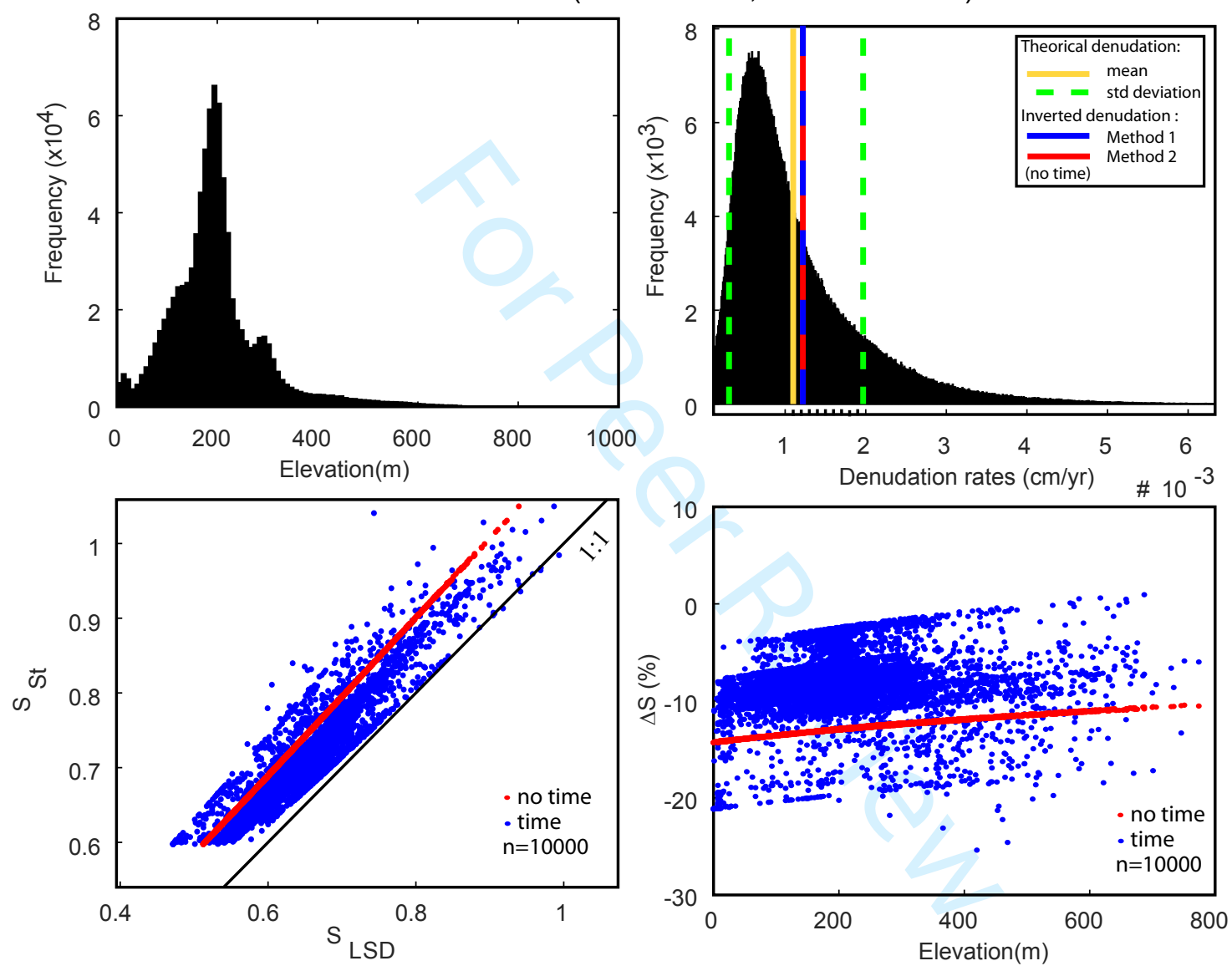

Fig. 7 

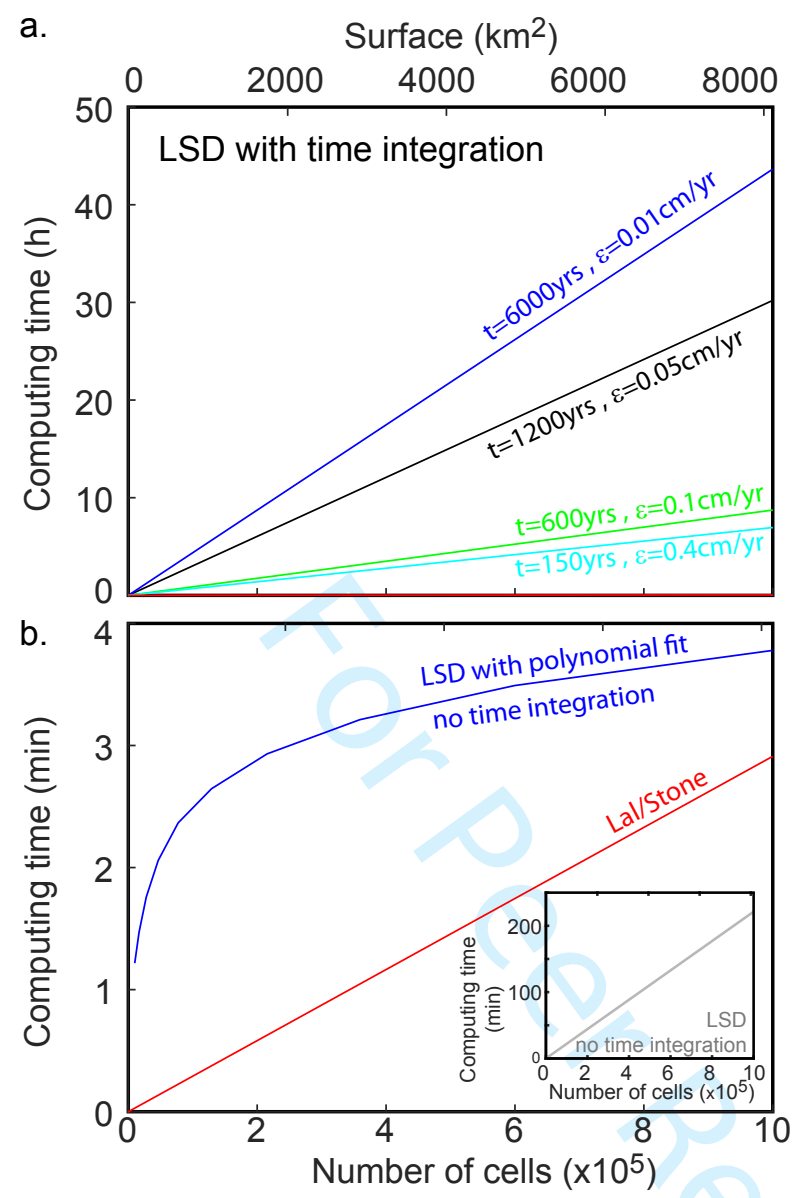

Fig. 8 
a.

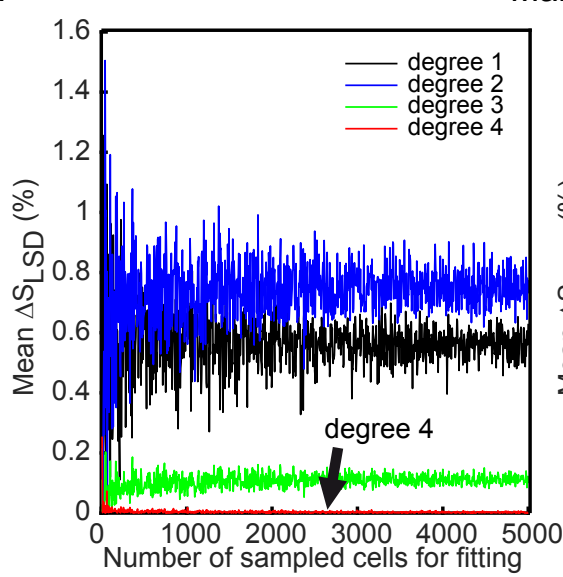

Marshyangdi basin (lat: N28.4305 ${ }^{\circ}$, Ion:E84.2354 ${ }^{\circ}$ )

b.

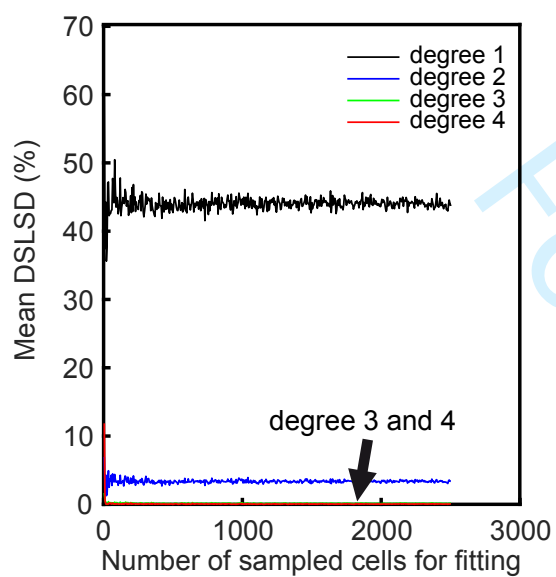

c.

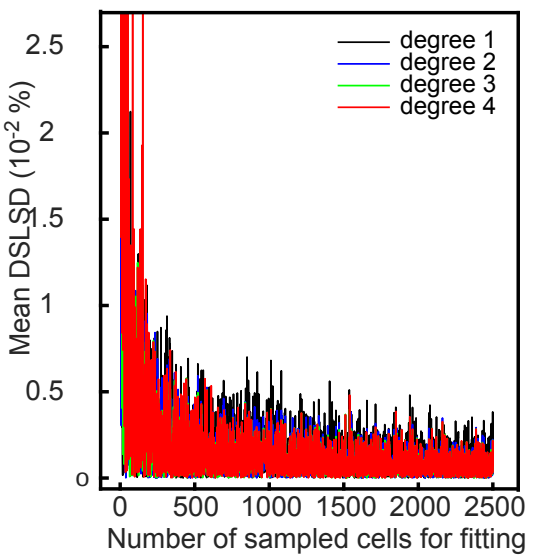

Fig. 9
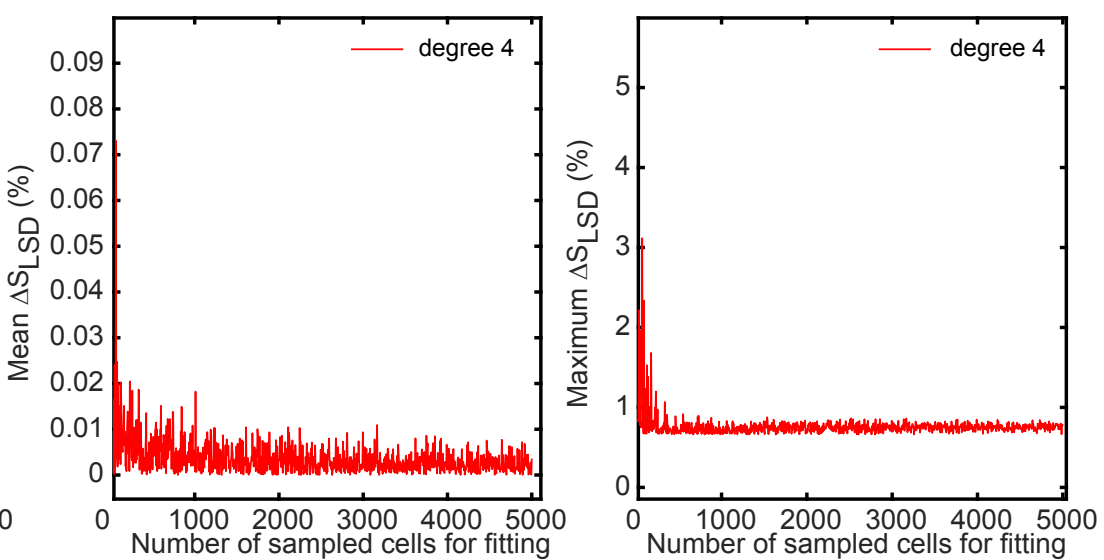

Susitna basin (lat: N62.7330 ${ }^{\circ}$, Ion:E211.3822 ${ }^{\circ}$ )
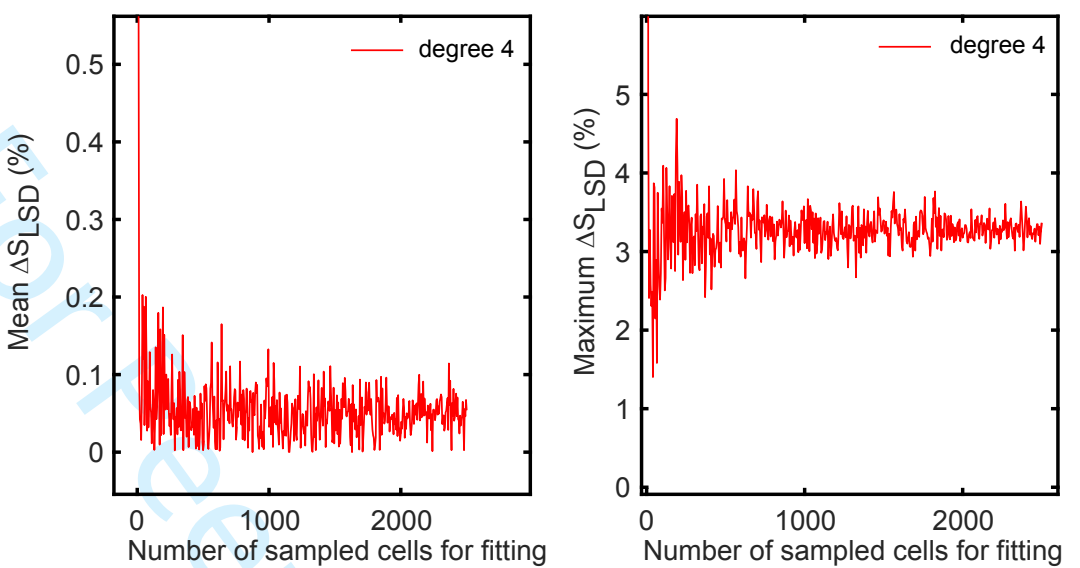

Maroni basin (lat: N3.4683 ${ }^{\circ}$, lon:E305.2154 ${ }^{\circ}$ )
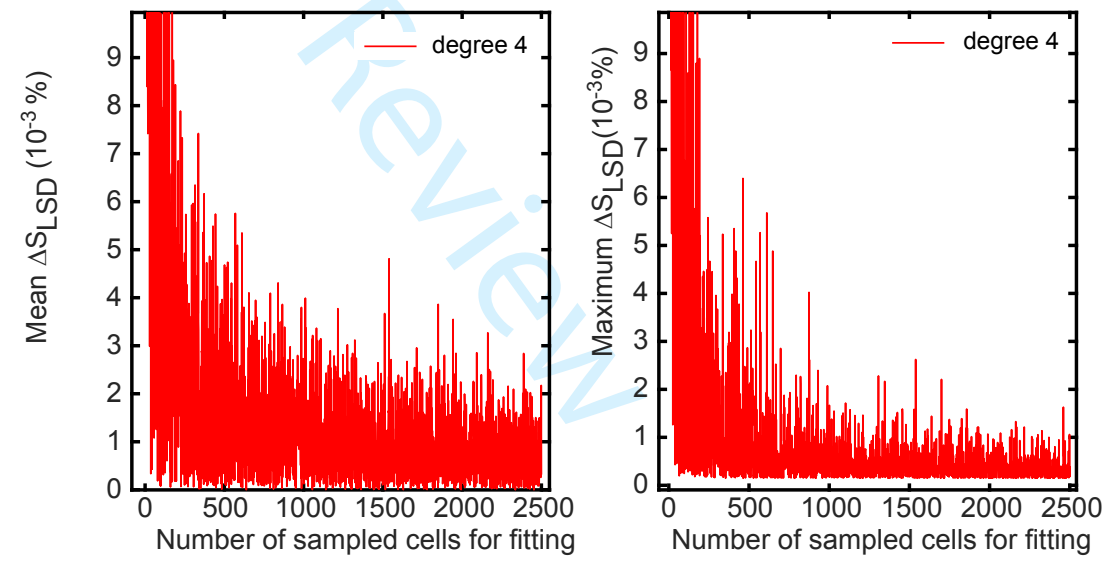


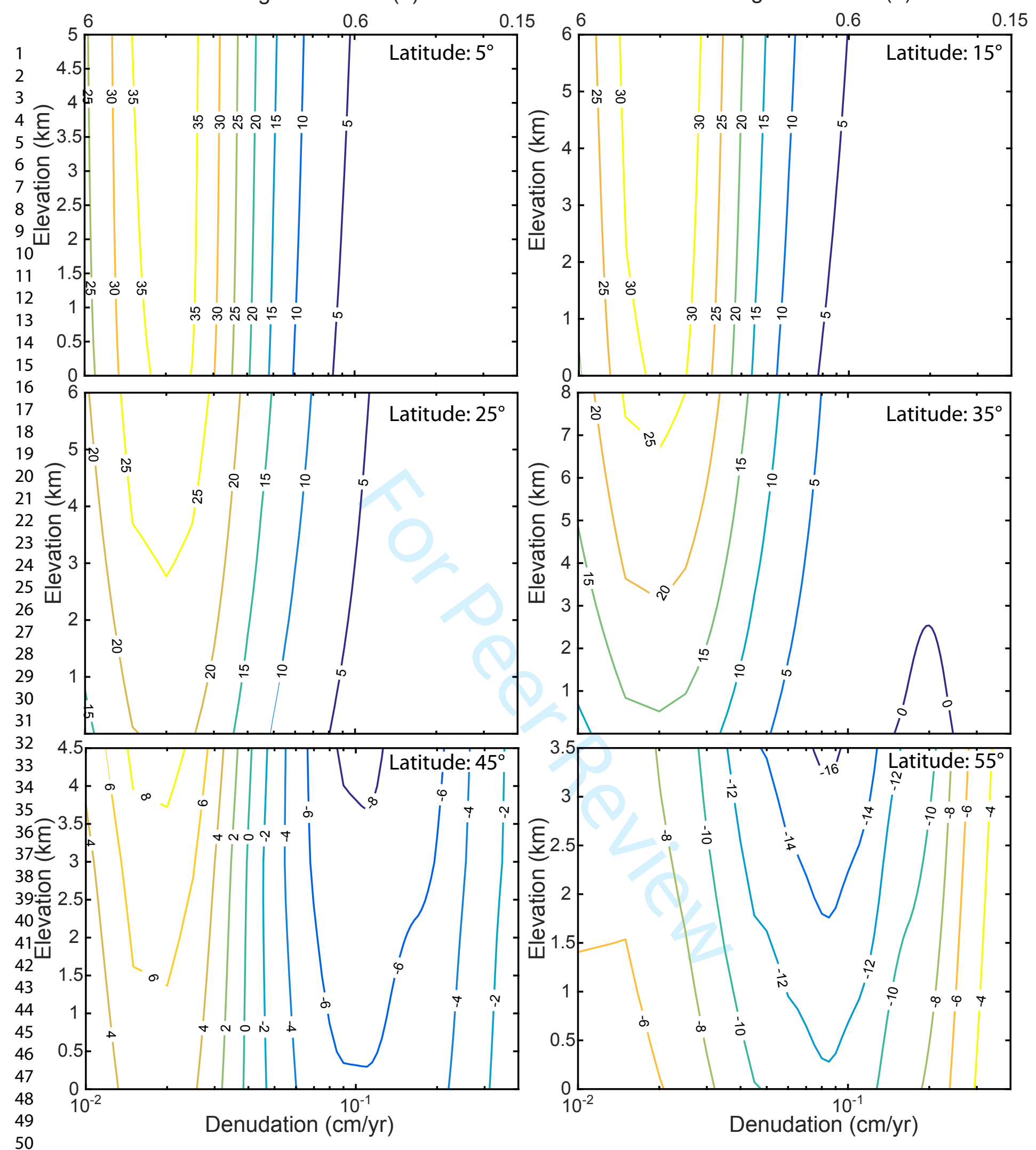

Fig. 11 


\title{
Online repository of " BASINGA: a cell-by-cell GIS toolbox for computing BASIN averaGe scaling factors, cosmogenic production rates and denudation rAtes"
}

\author{
Julien Charreau, Pierre-Henri Blard, Jéna Zumaque, Léo C.P. Martin, Tony Delobel and Lucas Szafran
}

\section{I- Technical description of Basinga}

\section{General overview of Basinga}

Basinga comprises two tools and their associated interfaces (Figs. A and B). The Production rates tool (Fig. A) calculates the basin average production rates based on the latitude and altitude of each cell of the studied basins (Fig. C). The minimum requirements are a raster file of the DEM and a shape file of the studied drainage basin (Fig. C).

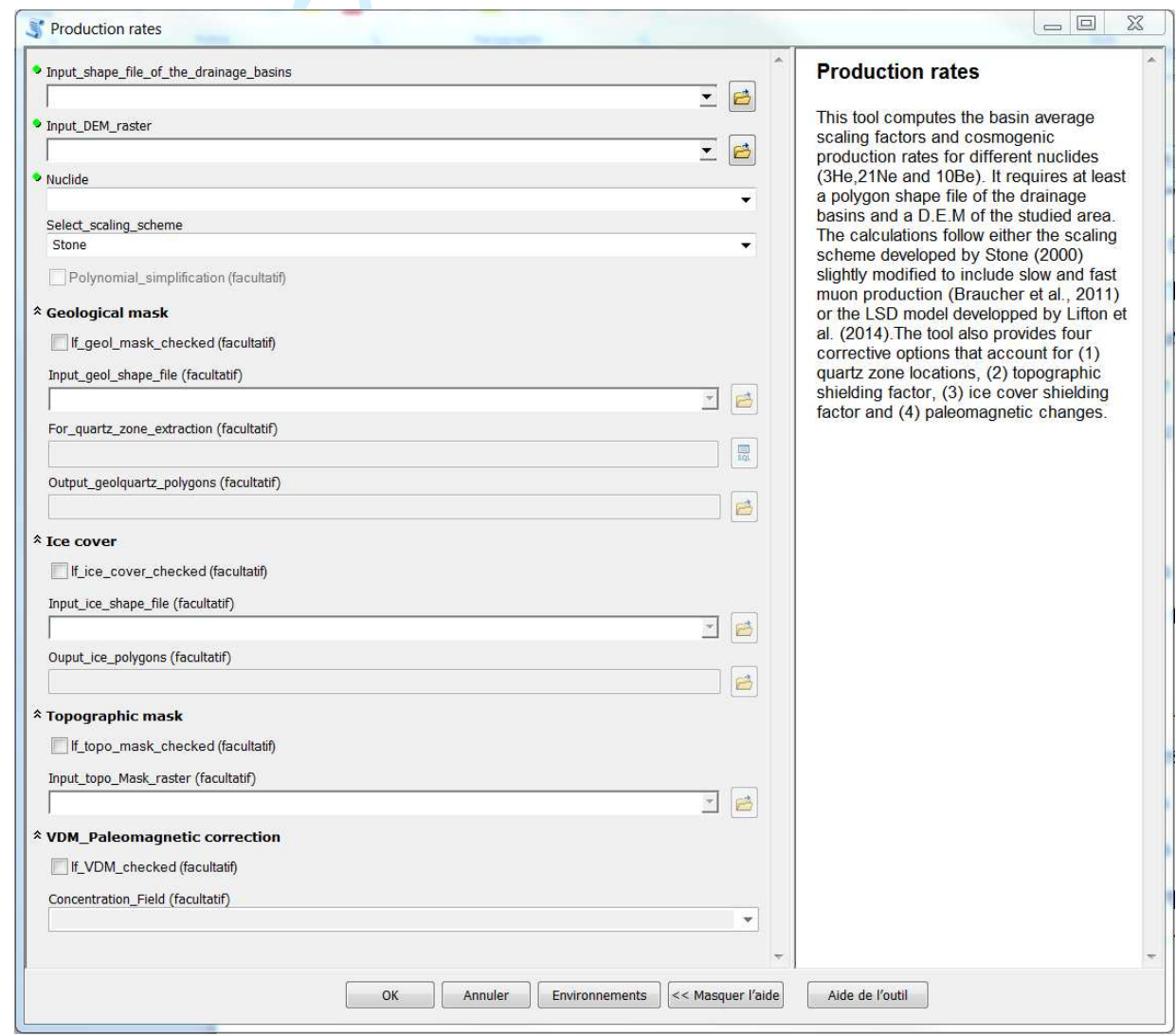

Fig. A: Production rates tool interface in ArcMap. This is the main interface where the user must specify at least the shape file of the drainage basin and the DEM. The other fields remain optional and can be activated if required by checking the corresponding boxes. A detailed help file is provided for each of the fields and is displayed on the right-hand side of the tool by clicking the "Show Help" button in the bottom right corner. 
The results of the calculations are stored in the attribute table of the basin shape file (Fig. C) following the nomenclature described in Table A. The Production rates tool can also correct the basin average value for paleomagnetic variations if the cosmogenic concentration at the outlet is known. The Denudation rates tool (Fig. B) calculates the denudation rates according to method 1 , the basin average production rates previously calculated using the Production rates tool and the cosmogenic concentration measured at the outlet. The latter must be already stored in the attribute table of the basins' shape file. The results are also returned in the attribute table of this input file.

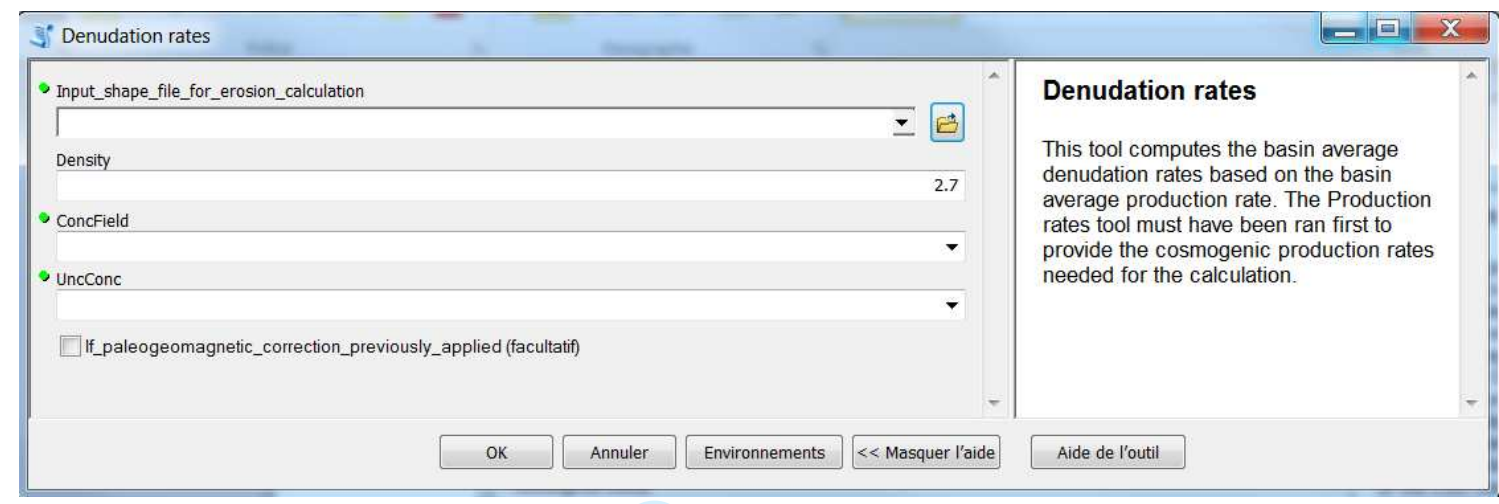

Fig. B: Denudation rates tool interface. The user must specify the path to the shape file where the concentrations in ${ }^{10} \mathrm{Be}$ and their uncertainties are stored. This file must include the cosmogenic production rates calculated using the Production rates tool. The fields for the ${ }^{10} \mathrm{Be}$ concentrations and their uncertainties must be specified and the box underneath the fields must be checked if the correction for paleomagnetism was carried out during the previous calculations.

\section{Topographic shielding}

This option requires an additional raster that provides the shielding factor (from 0 to 1 ) for each cell of the studied region. This correction can be applied either to the entire watershed or only to restricted regions (see below). The shielding factor raster can be independently computed in ArcGIS ${ }^{\circledR}$ using the approach developed by Codilean (2006), which is available upon request from these authors and can thus be easily integrated in Basinga without any further work. Their tool is based on the Relief Shadow Modeling method, which accounts for both Self-shadows and Cast-shadows (Codilean, 2006). The user is however free to choose any other topographic shielding computation as long as it can be converted into a raster file. It must strictly share the same coordinate system (i.e. geographic), resolution and shape of the original DEM. 


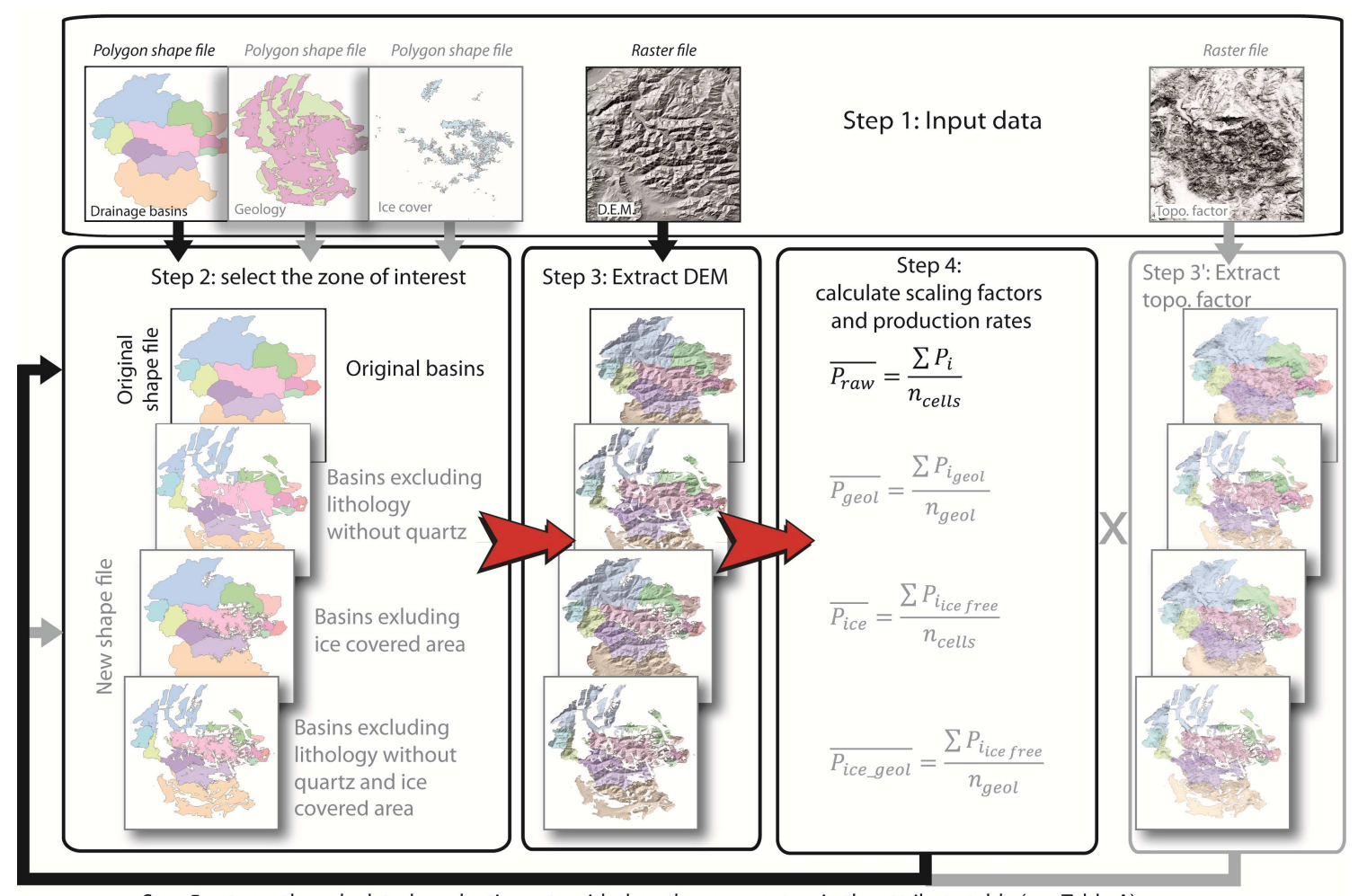

Step 5: returns the calculated production rate with the other parameters in the attribute table (see Table A)

Fig. C: Work flow of the Production rates tool. The tool mainly works in 5 steps. The user must first provide the input data corresponding to the corrective options chosen (Step 1). The tool then first selects and extracts the corresponding zone of interest (Steps 2 and 3). At this point, it may create a new shape file if the corrections for geology and ice have been selected. It then calculates the cosmogenic scaling factors and cosmogenic production rates for each individual cell and averages the values over the basins. Finally, it returns the calculated values to the attribute table of either the original shape file or of a new shape file created when the region of interest was selected.

\section{Lithology}

The user may exclude a region of undesired lithology using a SQL interface and expression (Fig. D) from an independent polygon shape file of the geology, which includes, in the attribute table, the necessary lithological information. Once selected, the desired geological regions are cut out from the original polygon of the basins and the tool creates a newly polygon shape file of the studied watershed in which it calculates the cosmogenic production rates. The production rates are therefore calculated and averaged only in this restricted region and may also include a correction for topographic shielding if the former option has been checked. The calculated parameters are stored in the attribute table of this newly created shape file (Fig. C and Table A). 
Table A. List and description of the different fields generated by the Production rates and Denudation rates tools.

\begin{tabular}{|c|c|c|}
\hline Fields & Description & Units \\
\hline Pixels & Number of cells encountered in the area of the original catchment ${ }^{a}$ & - \\
\hline Alt_ave & Catchment-averaged altitude & $(\mathrm{m})$ \\
\hline LAT_ave & Catchment-averaged latitude & Decimal degrees ${ }^{b}$ \\
\hline H_ave & Catchment-averaged atmospheric pressure & $\mathrm{hPa}$ \\
\hline Time & Equivalent time of exposure & $\mathrm{yr}$ \\
\hline Topo_fc* & Catchment-averaged topographic shielding factor & - \\
\hline Pneu_ ${ }_{-}^{1}$ & Catchment-averaged ${ }^{10} \mathrm{Be}$ nuclides produced by spallation ${ }^{\mathrm{b}}$ & atoms. $\mathrm{g}^{-1} \cdot \mathrm{yr}^{-1}$ \\
\hline Psm ${ }^{1}$ & Catchment-averaged ${ }^{10} \mathrm{Be}$ nuclides produced by slow muon capture ${ }^{\mathrm{b}}$ & atoms. $g^{-1} \cdot \mathrm{yr}^{-1}$ \\
\hline $\mathrm{Pfm}_{-}{ }^{1}$ & Catchment-averaged ${ }^{10} \mathrm{Be}$ nuclides produced by fast muon capture ${ }^{\mathrm{b}}$ & atoms. $\mathrm{g}^{-1} \cdot \mathrm{yr}^{-1}$ \\
\hline $\mathrm{SFn}_{-}{ }^{1}$ & Catchment-averaged scaling factor for spallation & - \\
\hline $\mathrm{SFf}_{-}{ }^{1}$ & Catchment-averaged scaling factor for fast muogenic production & - \\
\hline $\mathrm{SFs}_{-}^{-}$ & Catchment-averaged scaling factor for slow muogenic production & - \\
\hline Nuclide $^{2}$ & Number that records the nuclide selected for the last calculation & - \\
\hline Option $^{3}$ & Number that records the options selected for the last calculation & - \\
\hline Scaling $^{4}$ & Number that records the scaling selected for the last calculation & - \\
\hline
\end{tabular}

*These fields are directly related to two different corrective options and may not appear if not requested.

${ }^{a}$ If the correction for lithology has been activated, this number excludes the zones without quartz.

${ }^{\mathrm{b}}$ Negative values represent southern latitudes.

${ }^{1}$ May be followed by one or more indicative letters according to any optional corrections selected by the user (G: Geology (lithology); T: Topographic shielding factor; I: Ice cover shielding factor; P: Paleomagnetic changes). Of note, as the paleomagnetic results are computed independently (see section 4.6), any time this option is selected, these fields will appear twice: first referred to with all options except paleomagnetic changes activated, and second with a "P" at the end indicating the rate corrected for past variations in the Earth's magnetic field.

${ }^{2} 3\left({ }^{3} \mathrm{He}\right), 10\left({ }^{10} \mathrm{Be}\right)$ or $21\left({ }^{21} \mathrm{Ne}\right)$

${ }^{3} 0$ : Lal/Stone, 1: LSD.

4 1: GTI, 2: GI, 3:TI, 4: I, 5:GT, 6: G, 7: T and 8: no option selected

4. Ice cap

To run this optional tool, the ice cover must be entered as a polygon shape file (Figure $3)$. The modern ice cover can be downloaded as a shape file free of charge from the Global Land Ice Measurements from Space (GLIMS) website (http://www.glims.org), which provides a thorough and frequently updated glacier database (Armstrong et al., 2005; Raup et al., 2007). Nevertheless, cosmogenic nuclides may average out denudation rates over long time scales $\left(10^{2}-10^{5}\right.$ years $)$ especially in slowly eroding areas. However, glacial coverage has changed over time, which may induce a significant bias in the calculated production rate. Delunel et al. (2010) for example found it more relevant to consider ancient glacial extent reconstruction rather than modern glacial coverage and built a polygon shape file accordingly.

Once the paleoglacial cover shape file has been selected, the tool will first execute the main process to provide the total number of cells of the entire drainage basin, and it will then recalculate the mean production rate excluding the glacial zones. A new shape file of the 
drainage basin is created, including an attribute table that provides the results of the calculation (Error! Reference source not found.). Even if the ice cover correction box has been checked, the uncorrected raw production rate and scaling factors remain stored in the attribute table as before, along with the corrected values for ice cover. Note that, again, this correction for ice can be applied independently from the other options. If the quartz-free areas were excluded, the correction for ice is applied to this restricted area only.

a.

\begin{tabular}{|r|r|r|l|l||}
\hline & \multicolumn{1}{|c|}{ Lithology } & & \multicolumn{1}{c|}{ Quartz } \\
\hline 0 & Shape & ID & & no \\
\hline 1 & Polygone & 1 & Sedimentary cover & no \\
\hline 2 & Polygone & 2 & Sedimentary cover & no \\
\hline 3 & Polygone & 4 & Sedimentary cover & yes \\
\hline 4 & Polygone & 5 & Sedimentary cover & no \\
\hline
\end{tabular}

b.

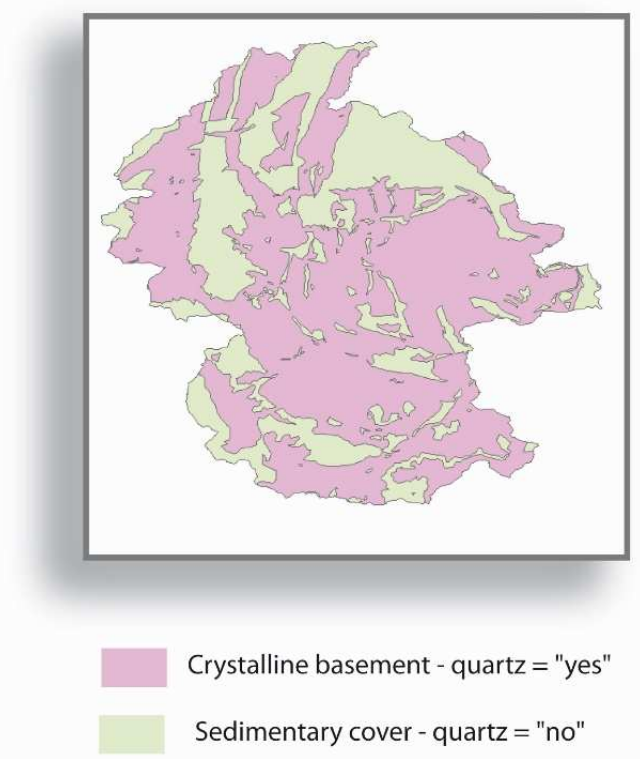

c.

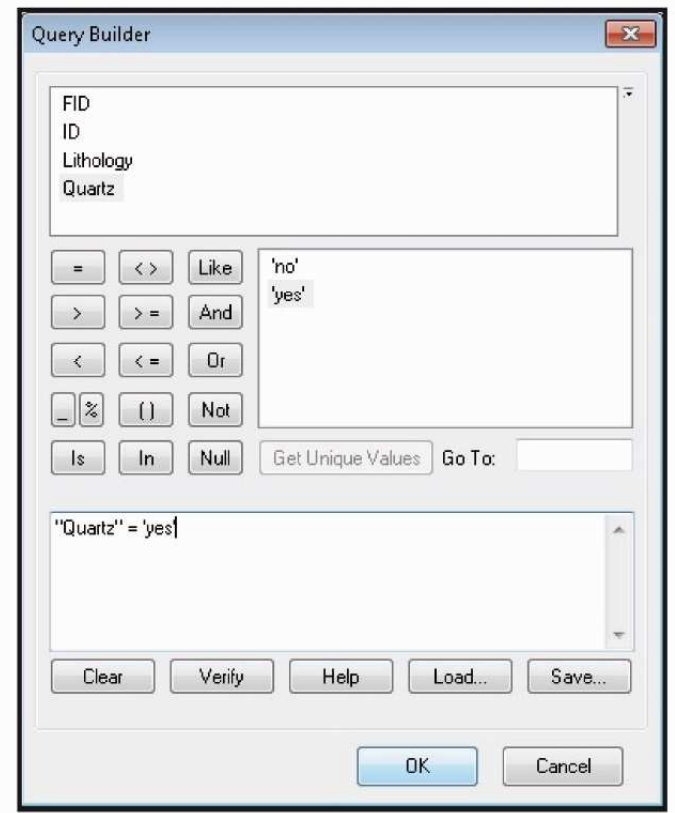

Fig. D: a. Example of an attribute table providing lithological information and specifying the presence or absence of quartz in an independent field (e.g. the field named 'Quartz'); b. Example of a shape file showing the polygons associated with the attribute table where the lithological information is given (after Delunel et al. (2010)); c. SQL interface open once the correction for lithology is selected. To compute the production rate in the region with quartz only (e.g. 'Crystalline basment') the user must specified a SQL expression (e.g. 'Quartz' = 'yes') which selects the correct polygons from the shape file accordingly. 


\section{II- Getting started with Basinga}

\section{ArcGIS}

System requirements

Basinga requires Windows 7 version or later and ArcGIS 10.1 or later. The extensions Spatial Analyst and 3D Analyst must also be installed and activated. Python 2.7 or later must be installed and include the NumPy and SciPy libraries. The latter are two open source libraries for scientific calculation and are provided in the online files or can be freely downloaded from the web (see for example: http://www.scipy.org/scipylib/download.html). The computer must be configured with the point as a decimal symbol (Start button $\rightarrow$ Control Panel $\rightarrow$ Clock, Language and Region $\rightarrow$ Region and Language $\rightarrow$ Format $\rightarrow$ Additional settings $\rightarrow$ Decimal symbol).

\section{Installation}

The downloaded folder provides the two Python scripts and the Basinga toolbox ('Basinga.tbx'), which was configured to include both the Production rates and Denudation rates tools. First, add the Basinga toolbox to the ArcToolbox (Open ArcToolbox $\rightarrow$ right click $\rightarrow$ Add Toolbox). More details can be found in the ArcGIS online resources, which provide documentation, help and tutorials. See for example:

http://webhelp.esri.com/arcgisdesktop/9.3/tutorials/gp/GP_1_4.htm

The links to the Python Scripts must be specified before starting any process (click on the added Basinga toolbox $\rightarrow$ right click on Production rates $\rightarrow$ Properties $\rightarrow$ Source $\rightarrow$ script file, repeat the operation for the Denudation rates tool).

\section{Changing the main cosmogenic parameterization}

\section{SLHL parameters}

The normalized surface production rates at Sea Level and High Latitude (SLHL) can be easily changed if needed by editing the script "Prod_rates.py" as follows: right click on "Prod_rates.py" $\rightarrow$ Edit with IDLE (editing can be performed by opening the file with MSWord or any simple text editor such as Notepad or Wordpad). Then modify the parameters from line 68:

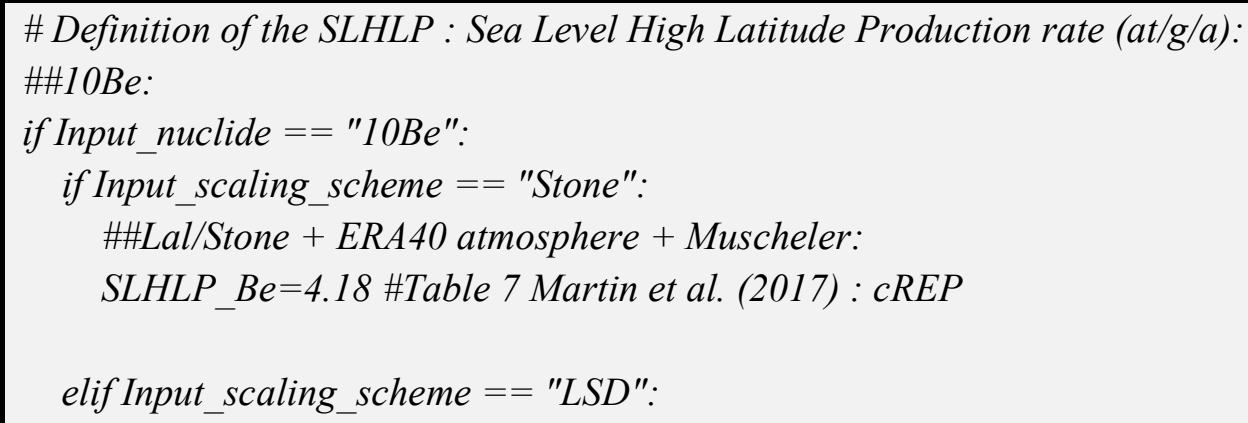


elif Input_nuclide $==$ "3He":

\#\#lease note that the code was originally written for 10Be only, for simplicty we keep the same for the parameters with "_Be" but it does consider different nuclide

if Input_scaling_scheme $==$ "Stone":

\#\#Lal/Stone + ERA40 atmosphere + Muscheler:

SLHLP_Be=122 \#Table 7Martin et al. (2017) : cREP

elif Input_scaling_scheme $==$ "LSD":

\#\#LSD + ERA40 atmosphere + Muscheler:

SLHLP_Be $=125$ \#Table 7 Martin et al. (2017) : cREP

nuclide $=3$

elif Input_nuclide $==" 21 \mathrm{Ne} "$ :

\#\#Please note that the code was originally written for 10Be only, for simplicty we keep the same for the parameters with "_Be" but it does consider different nuclide

if Input_scaling_scheme $==$ "Stone":

\#\#Lal/Stone + ERA40 atmosphere + Muscheler:

SLHLP_Be=4.18/4.12 \#10Be/21Ne=4.12+/- 0.17 see Kober et al., EPSL 2011 and Table 7 Martin et al. (2017) : cREP

elif Input_scaling_scheme $==$ "LSD":

\#\#SD + ERA40 atmosphere + Muscheler:

SLHLP_Be=4.14/4.12 \#10Be/21Ne=4.12+/- 0.17 see Kober et al., EPSL 2011 and Table 7 Martin et al. (2017) : cREP

nuclide $=10$

SLHLP_Be_neutron $=f s p * S L H L P \_B e$

SLHLP_Be_fastmuon $=f m u \_$fastmuon $* S L H L P \_B e$

SLHLP_Be_slowmuon $=f m u \_s l o w m u o n * S L H L P \_B e$

A complete list of the references used to set these parameters is given in the main text. The SLHL values also depend on the production rate between the different particles, which can be changed if needed in lines 34 to 37 :

\#production rate between the different particles at SLHL:

fsp $=0.9886$ \#Braucher et al.

fmu_slowmuon $=0.0027$ \# Braucher et al.

fmu_fastmuon $=0.0087$ \# Braucher et al. 


\section{Atmospheric attenuation lengths}

The atmospheric attenuation lengths were specified after Braucher et al. (2011). These can easily be changed by editing "Prod_rates.py" to modify the values in lines 39 to 41 of the code as needed:

\#Atmospheric attenuation (g.cm-2)(Braucher et al., EPSL 2011):

at_attenuation_fastmuon $=510$

at_attenuation_slowmuon $=260$

\section{Attenuation lengths in rocks}

The cosmogenic attenuation lengths in the rocks required to calculate the denudation rates are given lines 25 to 31 of the "Denudation.py" script as follows:

\#Attenuation lenght (g.cm-2)(Braucher et al., EPSL 2011):

lght_att_n=160.0

lght_att_n=float(lght_att_n)

lght_att_fm $=4320.0$

lght_att_fm=float(1ght_att_fm)

lght_att_sm $=1500.0$

lght_att_sm=float(lght_att_sm)

" $n$ " refers to neutrons, "fm" to fast muons and "sm" to slow muons. These values may be changed if needed.

\section{Uncertainties in ${ }^{10}$ Be cosmogenic production rates}

The uncertainties in ${ }^{10}$ Be cosmogenic production rates are specified in the Denudation.py script, for the nucleogenic production:

\#Uncertainties on the 10Be nucleogenic production rates:

U_sm $=0.5$

$U_{-} \mathrm{fm}=0.5$

and for spallation:

def nuclideSelected(nuclide,scaling):

\#Table 7Martin et al. (2017) : cREP

if scaling $==1: \# \mathrm{Lal} / \mathrm{St}$ scaling + ERA40 atmosphere + Muscheler:

if nuclide $==10$ :

U_spal $=0.048$

elif nuclide $==3$ :

U_spal $=0.0103$

elif nuclide $==21$ :

U_spal $=0.048$ 
elif scaling == 0:\#\#LSD scaling + ERA40 atmosphere + Muscheler:

if nuclide $==10$ :

U_spal $=0.063$

elif nuclide $==3$ :

U_spal $=0.048$

elif nuclide $==21$ :

U_spal $=0.063$

return U_spal

\section{QGIS}

\section{System requirements}

Basinga is fully functional on Windows and Mac OS with QGIS versions 2.8 and 2.14. It should also work on Linux systems but it has not yet been tested. All versions of QGIS can be downloaded from the QGIS website (https://www.qgis.org/fr/site/forusers/download.html).

Basinga requires the NumPy and SciPy libraries to be installed for the 2.7 python interpreter of QGIS. Both are open source and available online:

https://www.scipy.org/

http://www.numpy.org/

Follow the installation instructions given online or use pip to perform the task. Make sure that both libraries are installed for the python interpreter of QGIS and not for other software. Basinga requires the GDAL/OGR processing scripts so it is necessary to ensure that the GdalTools extension is installed and activated. The default installation of QGIS usually performs this.

To install Basinga follow these instructions:

- Close QGIS if necessary, and copy and paste the Basinga folder into the plugins directory of QGIS. The default path for Windows users is: "C:\Users\YourUserAccount \.qgis2 \python\plugins"

For OSX users: "/Applications/QGIS.app/Contents/Resources/python/plugins"

If the "plugins" folder does not exist, create it.

- Launch QGIS. Go to Plugins > Manage and Install Plugins...

First ensure to check the box "Show also experimental plugins" in the Settings tab. Then look for Basinga and activate it.

That's it! Basinga is now installed.

For more details on plugins visit the QGIS online documentation:

http://docs.qgis.org/2.8/en/docs/training_manual/qgis_plugins/index.html

If the plugin cannot be loaded, make sure that the Basinga folder contains the following files : "_init_.py" , "Denudation_process.py", "icon.png", "metadata.txt", "P_E_process.py", "P_E_process_dialog.py", "P_E_process_dialog_base.ui", "P_E_process_dialog_help.ui", 
"P_E_process_dialog_sql.ui", ～"parameters_definition.py", ～"PR_processes.py", "prod_rate_functions.py", "resources.py", "ressources.qrc".

\section{Changing the main cosmogenic parameterization}

All cosmogenic parameters used can be accessed and changed if needed. In order to do so, open the python file "parameters_definition.py" with any text editor (as Notepad or with python IDLE).

The normalized surface production rates at Sea Level and High Latitude (SLHL) can be found starting at lines 2075 of the code. If the cosmogenic production rates for nuclides other than $10 \mathrm{Be}$ are needed, these values may be changed accordingly.

if Input_nuclide == "10Be":

if Input_scaling_scheme $==$ "ls":

\#\#Lal/Stone + ERA40 atmosphere + Muscheler:

SLHLP_Be=4.18 \#Table 7 Martin et al. (2017) : cREP

nuclide $=10$

else:

\#\#LSD + ERA40 atmosphere + Muscheler:

SLHLP_Be=4.14 \#Table 7 Martin et al. (2017) : cREP

nuclide $=10$

elif Input_nuclide == "3He":

\#\#Please note that the code was originally written for $10 \mathrm{Be}$ only, for simplicty we keep the same for the parameters with "_Be" but it does consider different nuclide

if Input_scaling_scheme == "ls":

\#\#Lal/Stone + ERA40 atmosphere + Muscheler:

SLHLP_Be=122 \#Table 7Martin et al. (2017) : cREP nuclide $=3$

else:

\#\#LSD + ERA40 atmosphere + Muscheler:

SLHLP_Be=125 \#Table 7 Martin et al. (2017) : cREP

nuclide $=3$

elif Input_nuclide $==$ " $21 \mathrm{Ne} "$ :

\#\#Please note that the code was originally written for $10 \mathrm{Be}$ only, for simplicty we keep the same for the parameters with "_Be" but it does consider different nuclide

if Input_scaling_scheme == "ls":

\#\#Lal/Stone + ERA40 atmosphere + Muscheler:

SLHLP_Be=4.18/4.12 \#10Be/21Ne=4.12 +/- 0.17 see Kober et al., EPSL 2011 and

Table 7 Martin et al. (2017) : cREP nuclide $=10$

else:

\#LSD + ERA40 atmosphere + Muscheler: 
The values of the SLHL also depend on the production rate between the different particles, which can be changed if needed in the file "Parmaters_definition.py":

\#production rate between the different particles at SLHL:

fsp $=0.9886$ \#Braucher et al.

fmu_slowmuon $=0.0027 \#$ Braucher et al.

fmu_fastmuon $=0.0087$ \# Braucher et al.

The atmospheric attenuation lengths were specified after Braucher et al. (2011). They can easily be changed in "Parmaters_definition.py":

\#Attenuation lenght (g.cm-2)(Braucher et al., EPSL 2011):

lght_att_n=160.0

lght_att_n=float(lght_att_n)

lght_att_fm $=4320.0$

lght_att_fm=float(lght_att_fm)

lght_att_sm $=1500.0$

lght_att_sm=float(lght_att_sm)

"n" refer to neutrons, "fm" to fast muons and "sm" to slow muons.

The cosmogenic attenuation lengths in the rocks required to calculate the denudation rates are given in the same file:

\# Atmospheric attenuation (g.cm-2)(Braucher et al., EPSL 2011):

at_attenuation_fastmuon $=510$

at_attenuation_slowmuon $=260$

The uncertainties in the cosmogenic production rates are specified in the Denudation_process.py script, for the nucleogenic production:

\#Uncertainties on the $10 \mathrm{Be}$ cosmogenic production rates:

\#U_spal=0.09 \#Balco et al. (2008) - we used instead the uncertianties given in Table 7 of Martin et al. (2017)

U_sm $=0.5$

$U_{-} \mathrm{fm}=0.5$ 
and for spallation:

def nuclideSelected(nuclide,scaling):

\#Table 7Martin et al. (2017) : cREP

if scaling == 1:\#Lal/St scaling + ERA40 atmosphere + Muscheler:

if nuclide $==10$ :

U_spal $=0.048$

elif nuclide $==3$ :

U_spal $=0.0103$

elif nuclide $==21$ :

U_spal $=0.048$

elif scaling == 0:\#\#LSD scaling + ERA40 atmosphere + Muscheler:

if nuclide $==10$ :

U_spal $=0.063$

elif nuclide $==3$ :

U_spal $=0.048$

elif nuclide $==21$ :

U_spal $=0.063$

return U_spal

\section{Changing the source code of Basinga}

If you wish to change the source code of Basinga, we recommend using python IDE and Qt Creator. The GUI was created with PyQt. We also recommend use of the plugins reloader plugin to gain time while testing. 